\title{
Bioprospecção de espécies de microalgas regionais do Nordeste do Brasil para aplicação na produção de biocombustíveis
}

\section{Elizandra Ribeiro de Lima Pereira ${ }^{1}$, Vilma Barbosa da Silva Araújo ${ }^{1}$, Evandro Bernardo de Lira ${ }^{1}$, Virgínia Maria Magliano Morais ${ }^{2}$, Cristiane Francisca da Costa Sassi ${ }^{1}$, Hélder Formiga Fernandes ${ }^{3}$, Marcos Barros de Medeiros ${ }^{4}$, Roberto Sassi $^{1}$ e Petrônio Filgueira de Athayde-Filho ${ }^{5}$}

${ }^{1}$ Universidade Federal da Paraíba. Centro de Ciências Exatas e da Natureza. Laboratório de Ambientes Recifais e Biotecnologia com Microalgas (LARBIM). Campus I. João Pessoa-PB, Brasil (CEP 58051-900). E-mail: elizandraribeiro00@gmail.com.

${ }^{2}$ Universidade Federal da Paraíba. Centro de Educação. Departamento de Fundamentação da Educação. Campus I. João Pessoa-PB, Brasil (CEP 58051-900).

${ }^{3}$ Universidade Federal da Paraíba. Centro de Ciências Exatas e da Natureza. Programa de Pós-Graduação em Desenvolvimento e Meio Ambiente. Campus I. João Pessoa-PB, Brasil (CEP 58051-900).

4Universidade Federal da Paraíba. Centro de Ciências Humanas Sociais e Agrárias. Programa de Pós-Graduação em Ciências Agrárias. Laboratório Clínica Fitossanitária. Departamento de Agricultura. Campus III. Areia-PB, Brasil (CEP 58220-000).

5Universidade Federal da Paraíba. Centro de Ciências Exatas e da Natureza. Laboratório de Pesquisa em Bioenergia e Síntese Orgânica (LPBS). Campus I. João Pessoa-PB, Brasil (CEP 58051-900).

Resumo. Apenas um número relativamente modesto de microalgas tem sido investigado a respeito da sua capacidade de produção de óleo e outros produtos de interesse biotecnológico. Foram avaliadas diferentes espécies de microalgas dulcícolas isoladas de diferentes tipos de ambientes aquáticos da região Nordeste do Brasil, quanto a sua capacidade de crescimento, produção de biomassa e composição bioquímica. As espécies foram cultivadas em meio sintético e seu desenvolvimento foi acompanhado por contagem de células e por análises de fluorescência in vivo, mantidas sob condições controladas de luz e temperatura até a fase estacionária, quando os experimentos foram interrompidos e a biomassa seca foi obtida por liofilização. Os resultados mostraram diferentes resultados no crescimento e composição bioquímica das espécies, com altos teores de carboidrato e produtividade em Scenedesmus obtusus (D209WC), Selenastrum gracilis (D458WC) e Xanthonema sp. (D464WC), com valores em 35,93\%, 35,79\% e 47,16\%, respectivamente. Quanto

Recebido

$26 / 12 / 2019$

Aceito

$20 / 08 / 2020$

Disponível on line $22 / 08 / 2020$

Publicado $31 / 08 / 2020$

Acesso aberto

ISSN 2359-1412/RBGAS-2019-0109/2020/7/16/24/809

Rev. Bras. Gest. Amb. Sustent.

http://revista.ecogestaobrasil.net 
ao perfil lipídico, Actinastrum hantzschii (D467WC) e Pediastrum duplex (D511WC) apresentaram um teor elevado de ácidos graxos saturados (48,04\%, 48,03\%), e Scenedesmus quadricauda (D125WC) destacou-se pelo alto perfil de ácidos graxos saturados $(51,26 \%)$ e monoinsaturados $(27,08 \%)$. Os melhores teores de produtividade lipídica foram registrados para Selenastrum gracilis (D458WC) (23,65\%), Pediastrum boryanum (D231WC) (23,07\%), Coelastrum sp. (D193WC) (22,20\%) e Synechocystis sp. (D331WC) $(21,35 \%)$. As microalgas também foram avaliadas quanto à extração e quantificação de compostos fenólicos por cromatografia líquida de alta eficiência, como também, determinação da atividade antioxidante através do sequestro dos radicais DPPH (2,2-difenil-1-picril-hidrazil) e ABTS + (2,2'azinobis(3-etilbenzotiazolina-6-ácido sulfônico)), concluindo que as dez cepas possuem uma boa atividade antioxidante frente aos métodos utilizados, com destaque para Scenedesmus quadricauda (D125WC), que apresentou valores máximos em relação às demais espécies. Considerando-se o rápido crescimento, produtividade, considerável teor lipídico e de carboidratos, melhor perfil em ácidos graxos saturados e monoinsaturados e demais análises Scenedesmus quadricauda (D125WC), Selenastrum gracilis (D458WC), Coelastrum sp. (D193WC) apresentam-se como possíveis fontes de matéria-prima para produção de biodiesel.

Palavras-chave: Antioxidantes; Biodiesel; Organismos fotossintetizantes.

Abstract. Bioprospecting of species of regional microalgae from the Northeast of Brazil for application in the production of biofuels. Only a relatively modest number of microalgae have been investigated regarding their capacity to produce oil and other products of biotechnological interest. Different species of freshwater microalgae isolated from different types of aquatic environments in the Northeast Region of Brazil were evaluated in terms of their growth capacity, biomass production and biochemical composition. The species were grown in synthetic media and their development was accompanied by cell counting and fluorescence analysis in vivo, kept under controlled conditions of light and temperature until the stationary phase, when the experiments were interrupted and the dry biomass was obtained by freeze-drying. The results showed different results in the growth and biochemical composition of the species, with high levels of carbohydrate and productivity in Scenedesmus obtusus (D209WC), Selenastrum gracilis (D458WC) and Xanthonema sp. (D464WC), with values of $35.93 \%, 35.79 \%$ and $47.16 \%$, respectively. As for the lipid profile, Actinastrum hantzschii (D467WC) and Pediastrum duplex (D511WC) presented a high content of saturated fatty acids (48.04\%, 48.03\%), and Scenedesmus quadricauda (D125WC) stood out for the high profile of acids saturated (51.26\%) and monounsaturated $(27.08 \%)$. The best levels of lipid productivity were recorded for

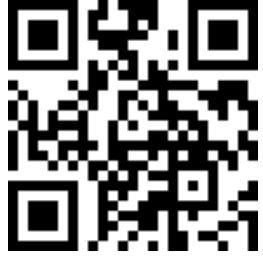

ORCID

(C) $0000-0003-3191-182 \mathrm{X}$ Elizandra Ribeiro de Lima Pereira

D) 0000-0001-9973-4060 Vilma Barbosa da Silva Araújo

(ㄷ) 0000-0001-5936-4747 Evandro Bernardo de Lira

D) 0000-0001-8083-1979

Virgínia Maria

Magliano Morais

(1) $0000-0002-4980-1779$

Cristiane Francisca da Costa Sassi

(D) 0000-0002-0370-0673

Hélder Formiga

Fernandes

() 0000-0002-1633-3227

Marcos Barros de

Medeiros

(ㄷ) 0000-0001-9586-5872

Roberto Sassi

(ㄷ) 0000-0003-0982-8261

Petrônio Filgueira de

Athayde-Filho 
Selenastrum gracilis (D458WC) (23.65\%), Pediastrum boryanum (D231WC) (23.07\%), Coelastrum sp. (D193WC) (22.20\%) and Synechocystis sp. (D331WC) (21.35\%). Microalgae were also evaluated for the extraction and quantification of phenolic compounds by high performance liquid chromatography, as well as the determination of antioxidant activity by sequestering the radicals DPPH (2,2-diphenyl-1-picryl-hydrazyl) and ABTS + (2,2'azinobis (3-ethylbenzothiazoline-6-sulfonic acid)), concluding that the ten strains have a good antioxidant activity compared to the methods used, with emphasis on Scenedesmus quadricauda (D125WC), which presented maximum values in relation to other species. Considering the rapid growth, productivity, considerable lipid and carbohydrate content, better profile in saturated and monounsaturated fatty acids, and other Scenedesmus quadricauda (D125WC), Selenastrum gracilis (D458WC), Coelastrum sp. (D193WC) are possible sources of raw material for the production of biodiesel.

Keywords: Antioxidants; Biodiesel; Photosynthetic organisms.

\section{Introdução}

Trabalhos sobre bioprospecção de microalgas são essenciais para a exploração de novas espécies que possam ter aplicações biotecnológicas, dentre as existentes na natureza. $\mathrm{O}$ isolamento e a obtenção de culturas de espécies nativas, e a pesquisa posterior de compostos de interesse traz novas perspectivas no tocante à exploração de diversos metabólitos sintetizados por esses organismos, que cada vez mais ganham espaços em aplicações farmacológicas, químicas, na indústria de alimentos e energética.

Apontadas como uma das mais promissoras fontes de matérias-primas para a produção de biocombustíveis, as microalgas possuem grande potencial de produção de óleos em áreas reduzidas e não são utilizadas como insumos alimentícios. Elas utilizam a energia solar para converter o $\mathrm{CO}_{2}$ e água em biomassa, pois são organismos fotossintéticos que se desenvolvem em ambientes aquáticos, diferentemente do biodiesel tradicional, que é produzido através de plantas cultivadas na terra, como a cana-de-açúcar, a soja e o milho, que precisam de grandes áreas cultiváveis e podem comprometer a disponibilidade de alimento (Carneiro et al, 2018).

A pouca ou nenhuma dependência de variações sazonais nos cultivos em massa desses organismos, e à relativa estabilidade nos constituintes metabólicos por elas produzidos, acoplado ao alto rendimento de biomassa e de óleo em muitas espécies fazem das microalgas uma excelente fonte alternativa para a produção de bioenergia, incluindo o biodiesel, bioetanol, bioquerosene e biogás (Chisti, 2008; Lehr et al., 2009; Calixto, 2016).

Produzidos a partir de fontes de energia renováveis de forma a contribuir para a redução da emissão de gases nocivos ao ambiente, os biocombustíveis mais comumente utilizados são o biodiesel e bioetanol. Alguns autores, como Lobo et al. (2009) e BorgesCampos et al. (2010), definem o biodiesel como uma mistura de alquil ésteres de cadeia linear, obtido por meio da reação de transesterificação dos triglicerídeos de óleos e gorduras com álcoois de cadeia curta, o qual pode ser utilizado puro ou em misturas com o diesel de petróleo em diferentes proporções. Estima-se que, sob condições favoráveis de cultivo a produção de biodiesel a partir de óleos de microalgas poderia se situar entre 7,7 mil e 23 mil litros por hectare (Cardoso, 2012), valores estes que tendem a aumentar à medida que os estudos avançam. 
Em 2015, representantes de diversos ministérios do Governo Federal brasileiro assinaram a Resolução do Conselho Interministerial do Açúcar e do Álcool (CIMA) que ampliou o percentual obrigatório de adição de etanol anidro de $25 \%$ para $27 \%$ na gasolina comum (Brasil, 2014). E de acordo com a Agência Nacional do Petróleo, Gás Natural e Biocombustíveis (ANP), a Lei no 13.263/2016 (Brasil, 2016) alterou a Lei no 13.033/2014 (Brasil, 2014), estabelecendo um cronograma de aumento do teor do biodiesel, a partir de 2017, sendo que o incremento até março de 2017 seria de 8\%, até março de 2018, 9\% e até março de 2019, 10\% (Brasil, 2016).

Admite-se que a energia do futuro que possa atender grande parte das atividades humanas deverá ser dependente em grande parte do cultivo e processamento das microalgas (Meng et al., 2009; Gong e Jiang, 2011; Montero et al., 2011), razão pela qual esses organismos tem sido cada vez mais investigados a esse respeito. Desse modo, o estudo das microalgas na biotecnologia surge como um dos modernos processos microbiológicos que tem alavancado inúmeros trabalhos e frentes de pesquisa nas últimas décadas (Nagarajan et al., 2012).

Dentre esses estudos destacam-se o desenvolvimento de métodos de cultivo e engenharia de sistemas de cultivo, a engenharia metabólica, a fim de aumentar a produção lipídica, a tecnologia de colheita de biomassa, a tecnologia de conversão de biocombustíveis, a avaliação de custo-eficácia, bem como as implicações políticas (Ghosh et al., 2016).

O presente estudo teve o propósito de avaliar algumas cepas de microalgas isoladas da região Nordeste do Brasil quanto ao seu potencial para produção de biocombustíveis, quantificando suas taxas de crescimento celular e sua composição bioquímica.

\section{Materiais e métodos}

\section{Espécies estudadas e condições de cultivo}

Um total de dez espécies de microalgas dulcícolas, isoladas de diferentes tipos de ambientes aquáticos dos Estados da Paraíba (5), Bahia (1), Rio Grande do Norte (2) e Piauí (2), pertencentes à Coleção de Microalgas do Laboratório de Ambientes Recifais e Biotecnologia de Microalgas, da Universidade Federal da Paraíba, foram selecionadas para o estudo, nove das quais são clorofíceas e uma é cianobactéria (Tabela 1).

As espécies foram identificadas usando critérios diacríticos (Hindak, 1990), de acordo com suas características morfológicas, seguindo os procedimentos clássicos usados em ficologia e disponíveis em obras de referência (Rabenhorst e Geitler, 1932; Komarék e Anagnostidis, 2005; Bellinger e Sigee, 2013), dados publicados em artigos científicos e sites específicos como o Algaebase (Franceschini et al., 2009).

As espécies foram cultivadas em triplicatas em balões de $6 \mathrm{~L}$ de capacidade, contendo $5 \mathrm{~L}$ de meio de cultura WC preparado com água destilada e autoclavada (Guillard e Lorenzen, 1972). Os cultivos foram desenvolvidos em ambiente climatizado $\left(25^{\circ} \mathrm{C} \pm\right.$ $1^{\circ} \mathrm{C}$ ), com fotoperíodo de $12 \mathrm{~h}$ e iluminação de $150 \mu$ mol.fótons. $\mathrm{cm}^{2} . \mathrm{s}^{-1}$. Os frascos e cultura foram aerados com ar comprimido usando um minicompressor de membrana (RESUN AOC2).

O desenvolvimento dos cultivos foi feito por meio de contagens celulares em microscópio binocular Leica utilizando câmaras de Fuchs-Rosenthal, e também por medidas da fluorescência in vivo utilizando um fluorímetro (TURNER DESIGN 10005R). Os cultivos foram desenvolvidos até a fase estacionária, quando foram interrompidos. A biomassa produzida por cada espécie foi concentrada em centrífuga refrigerada, a $18{ }^{\circ} \mathrm{C} \mathrm{e}$ $3.500 \times \mathrm{g}$ por 20 min (Novatecnica, modelo NT825), congelada em ultrafreezer (Terroni, modelo 90LT), a $-30{ }^{\circ} \mathrm{C}$, seca em liofilizador (Terroni, modelo LS3000), pesada em balança analítica e mantida em refrigeração até o momento das análises. 
Tabela 1. Relação das microalgas selecionadas para estudo e respectiva procedência. 0 número entre parênteses refere-se ao código de tombamento da espécie no banco de culturas de microalgas do LARBIM/UFPB; PB= Estado da Paraíba; BA= Estado da Bahia; RN= Estado do Rio Grande do Norte; PI = Estado do Piauí.

\begin{tabular}{|l|l|c|l|}
\hline Cepa & \multicolumn{1}{|c|}{ Identificação } & $\begin{array}{c}\text { Grupo } \\
\text { Taxonômico }\end{array}$ & \multicolumn{1}{|c|}{ Procedência } \\
\hline D125WC & Scenedesmus quadricauda & Clorofícea & Balneário Pitimbu, PB \\
\hline D193WC & Coelastrum sp. & Clorofícea & Açude das Garças, Cajá, PB \\
\hline D209WC & Scenedesmus obtusus & Clorofícea & Tanque de Carpa, Alto do Mateus, PB \\
\hline D231WC & Pediastrum boryanum & Clorofícea & Ilha da Onça, Rio São Francisco, BA \\
\hline D331WC & Synechocystis sp. 1 & Cianobactéria & Lago Carcará, RN \\
\hline D458WC & Selenastrum gracilis & Clorofícea & Barragem do Rio Gramame, PB \\
\hline D459WC & Microspora sp. & Clorofícea & Açude Jardim Seridó, PB \\
\hline D464WC & Xanthonema sp. & Clorofícea & Aldeia Tramataia, viveiro carcinicultura, PB \\
\hline D467WC & Actinastrum hantzschii & Clorofícea & PARNA Sete Cidades, Fonte Milagres, PI \\
\hline D511WC & Pediastrum duplex & Clorofícea & PARNA Sete Cidades, Fonte Milagres, PI \\
\hline
\end{tabular}

Com os dados dos cultivos foram determinados a velocidade de crescimento $(k)$, calculada pela equação fornecida por Stein (1973), o tempo de cultivo, o rendimento máximo celular, bem como o rendimento da biomassa (peso seco do material colhido em cada experimento) e a produtividade de biomassa (PB), expressa em $\mathrm{g} \mathrm{L}^{-1} \cdot \mathrm{d}^{-1}$, conforme Griffith et al. (2009). Similarmente, os valores de produtividade em carboidrato e de produtividade em proteínas seguiram o mesmo procedimento.

\section{Análises químicas efetuadas nas biomassas obtidas}

Nas amostras de biomassa obtidas nos cultivos foram realizadas análises de proteínas, segundo o método de Lowry at al. (1951), adaptado por Derner et al. (2006), utilizando como padrão proteína de soro bovino preparada com gradiente de concentração de 0 - $400 \mu \mathrm{g} / \mathrm{mL}$ e leituras espectrofotométricas a $485 \mathrm{~nm}$ (Thermo Fisher Scientific Spectrophotometer, modelo Evolution 60S); carboidratos, pelo método de Kochert (1978), adaptado por Derner et al. (2006), usando padrão de glicose anidra preparada com gradiente de concentração de 0-400 $\mu \mathrm{g} / \mathrm{mL}$ e leituras espectrofotométricas a $485 \mathrm{~nm}$ (Thermo Fisher Scientific, Spectrophotometer Evolution 60S), e lipídios pelo método gravimétrico de Bligh e Dyer (1959), adaptado por Lourenço (2006), usando ultrassom para rompimento da parede celular e clorofórmio, metanol e água (1:2:2) como solventes extratores.

Os ésteres metílicos de ácidos graxos foram determinados por cromatografia em fase gasosa usando um cromatógrafo a gás Agilent 7890, equipado com detector FID e injetor split/splitless, usando uma coluna capilar DB-WAX (30 m x 0,25 mm x 0,25 $\mu \mathrm{m}$ ) e hidrogênio como gás de arraste. 0 procedimento seguiu (MENEZES et al., 2013) sendo os ésteres metílicos de ácidos graxos identificados pela comparação direta com amostras de oleaginosas de composição conhecida (soja), por injeção de padrões de referência de FAMEs (NuCheckPrep ${ }^{\circledR}$ ) e por análises via Cromatografia Gasosa de Alta Resolução acoplada a Espectrometria de Massas.

As 10 espécies de microalgas cultivadas foram submetidas a processo de extração para determinação da atividade antioxidante. Realizou-se uma extração sequenciada em gradiente crescente de polaridade utilizando-se o metanol como solvente. À massa de cerca de 1,0 g de cada amostra, adicionou-se 40,0 mL de metanol, sendo sonicadas em banho de gelo (Unique, modelo USC-1400A) em três intervalos de 30 min. Para extração, a amostra foi agitada por $3 \mathrm{~h}$ em temperatura ambiente, seguido da centrifugação do extrato 
a $5.000 \times g$ por 10 min e o sobrenadante recuperado. Depois de repetir o processo de extração, os dois sobrenadantes foram somados. Os extratos foram secos em estufa de circulação de ar (Solab, modelo SL102) a $35^{\circ}$ C. As amostras foram armazenadas, ao abrigo da luz, à temperatura ambiente até o momento de sua utilização. Os extratos foram preparados com água destilada na concentração de $5 \mathrm{mg} \cdot \mathrm{mL}^{-1}$ e armazenados em frascos âmbar, sob refrigeração até à sua utilização.

\section{Propriedades antioxidantes das dez espécies estudadas}

Obtenção dos extratos. Os reagentes utilizados nas metodologias de antioxidantes foram adquiridas de fontes diversas. A Merck (Darmstadt, Germany) forneceu o reagente Folin-Ciocalteau. Os padrões de ácido gálico, ácido ascórbico, DPPH (radical 2,2-difenil-1-picril-hidrazila), TROLOX (6-hidroxi-2,5,7,8-tetramethylchroman-2ácido carboxílico) e TPTZ (6-hidroxi-2,5,7,8-tetramethylchroman-2-ácido carboxílico) foram adquiridos da Sigma-Aldrich (St. Louis, MO). Demais reagentes como sulfato ferroso heptahidratado $\left(\mathrm{FeSO}_{4} .7 \mathrm{H}_{2} \mathrm{O}\right)$, cloreto férrico hexahidratado $\left(\mathrm{FeCl}_{3} \cdot 6 \mathrm{H}_{2} \mathrm{O}\right)$, carbonato de sódio $\left(\mathrm{Na}_{2} \mathrm{CO}_{3}\right)$ e acetato de sódio trihidratado $\left(\mathrm{CH}_{3} \mathrm{COONa}\right)$ foram adquiridos da Vetec Química Fina Ltda.

A biomassa das dez espécies de microalgas cultivadas foi submetida à extração sequenciada em gradiente crescente de polaridade com hexano $\left(\mathrm{C}_{6} \mathrm{H}_{14}\right)$, que é uma mistura de hidrocarbonetos saturados, constituído de 5 a 9 átomos de carbono, com faixa de destilação entre $62{ }^{\circ} \mathrm{C}$ e $74{ }^{\circ} \mathrm{C}$ (a $760 \mathrm{mmHg}$ ) e densidade entre 0,660 a $0,805\left(20 / 4{ }^{\circ} \mathrm{C}\right.$ ), sendo então um potencial reagente de arraste em extrações químicas.

Foram pesados $1,0 \mathrm{~g}$ de cada amostra e adicionado 40,0 $\mathrm{mL}$ de hexano, sendo sonicadas em banho de gelo (Unique, modelo USC-1400A) por 30 min. Para extração, a amostra foi agitada por três $\mathrm{h}$ em temperatura ambiente, seguido da centrifugação do extrato a $8.000 \mathrm{xg}$ por $10 \mathrm{~min}$ e o sobrenadante recuperado. Posteriormente, o processo de extração foi repetido e os dois sobrenadantes foram somados. 0 resíduo foi extraído duas vezes com 40,0 mL de etanol seguido por 40,0 mL de água destilada nas mesmas condições anteriormente descritas. Os extratos foram secos em estufa de circulação de ar (Solab, modelo SL102) a $35^{\circ} \mathrm{C}$. As amostras foram armazenadas ao abrigo da luz, à temperatura ambiente até o momento de sua utilização. Os extratos foram preparados com metanol na concentração de 5 mg.mL $\mathrm{mL}^{-1}$ e armazenados em frascos âmbar, sob refrigeração $\left(2-8^{\circ} \mathrm{C}\right)$ até sua posterior utilização.

Determinação dos compostos fenólicos totais. Determinaram-se os fenólicos totais das microalgas de acordo com o método colorimétrico Folin-Ciocalteu (Slinkard e Singleton, 1997). Utilizou-se uma curva de calibração de ácido gálico (2-200 mg.mL ${ }^{-1}$ ) para a estimativa da concentração de compostos fenólicos, sendo os resultados expressos como mg equivalente de ácido gálico (GAE) em cada grama de extrato.

Método de captura do radical DPPH. A capacidade dos antioxidantes de sequestrar o radical estável DPPH presentes nas amostras foi determinada de acordo com (Brand-Wilians et al., 1995). A partir de ensaios preliminares, a solução de DPPH (23,6 $\left.\mu \mathrm{g} \cdot \mathrm{mL}^{-1} \mathrm{em} \mathrm{EtOH}\right)$ foi adicionada às amostras do extrato obtendo uma concentração final de $150 \mu \mathrm{g} \cdot \mathrm{mL}^{-1}$. Montadas em triplicata, alíquotas de $90 \mu \mathrm{L}$ dos extratos foram misturadas com $210 \mu \mathrm{L}$ de etanol e $2.700 \mu \mathrm{L}$ da solução de DPPH $\left(23,6 \mu \mathrm{g} \cdot \mathrm{mL}^{-1}\right.$ em EtOH). As leituras foram realizadas após $30 \mathrm{~min}$ a $517 \mathrm{~nm}$, em espectrofotômetro UV-vis (Thermo Fisher Scientific, modelo Evolution 60S). Uma curva padrão foi preparada utilizando Trolox em concentrações de $\left(0,5\right.$ a $\left.5 \mu \mathrm{g} \cdot \mathrm{mL}^{-1}\right)$. Os resultados da atividade antioxidante foram expressos em $\mu \mathrm{M}$ Trolox. ${ }^{-1}$ extrato (atividade antioxidante equivalente ao Trolox). A capacidade de sequestrar radical livre foi expressa como percentual de inibição de oxidação do radical e calculado conforme equação a seguir: 


$$
\text { \% Inibição }=\left(\left(A_{\text {Extr }}-A_{D P P H}\right) / A_{D P P H}\right) * 100 \quad \text { (Eq. 1) }
$$

em solução.

Onde $A_{D P P H}$ é a absorvância da solução de DPPH e $A_{\text {Extr }}$ é a absorvância da amostra

Atividade sequestrante do radical livre ABTS (2,2-azinobis(3etilbenzotiazolina-6 ácido sulfônico). Conforme a metodologia descrita por Rufino et al. (2007b), a atividade antioxidante pelo método ABTS + (2,2-azinobis (3-etilbenzotiazolina6 ácido sulfônico), foi determinada. 0 radical ABTS foi preparado a partir da reação de $5 \mathrm{~mL}$ da solução estoque de ABTS $+7 \mathrm{mM}$ com $88 \mu \mathrm{L}$ da solução de persulfato de potássio $140 \mathrm{mM}$. Manteve-se essa mistura à temperatura ambiente por $16 \mathrm{~h}$. Após esse período o radical foi diluído em etanol P.A. (aproximadamente $1: 90 \mathrm{v} / \mathrm{v}$ ) até a obtenção do valor de absorbância de 0,700 a $734 \mathrm{~nm}$. Posteriormente, transferiu-se uma alíquota de $30 \mu \mathrm{L}$ com $3,0 \mathrm{~mL}$ do radical ABTS + dos extratos de cada espécie de microalga. A leitura foi realizada após 6 min de reação a $734 \mathrm{~nm}$, utilizando-se como branco o etanol. A curva padrão foi obtida utilizando-se Trolox em concentrações de $\mu \mathrm{M}$. Os resultados da atividade antioxidante foram expressos em $\mu \mathrm{M}$ Trolox.g ${ }^{-1}$ extrato (atividade antioxidante equivalente ao Trolox).

Atividade antioxidante pelo poder redutor do ferro (FRAP). Seguindo a metodologia de Rufino et al. (2006), Foram realizadas ao abrigo da luz e em triplicata as análises da atividade antioxidante dos extratos de microalgas. A solução do reagente FRAP foi preparada com $25 \mathrm{~mL}$ de tampão acetato $0,3 \mathrm{M}$, uma alíquota de 2,5 mL da solução TPTZ (2,4,6-Tris (2 piridil)-s-triazina) a $10 \mathrm{mM}$ e $2,5 \mathrm{~mL}$ de solução aquosa de cloreto férrico $20 \mathrm{mM}$. Foram adicionado $90 \mu \mathrm{L}$ de cada extrato em tubos, $270 \mu \mathrm{L}$ de água destilada, seguido de 2,7 mL do reagente FRAP. Após homogeneização, os tubos foram mantidos em banho-maria a $37^{\circ} \mathrm{C} .0$ espectrofotômetro UV-vis (Thermo Fisher Scientific, modelo Evolution 60S) foi calibrado com o reagente FRAP e as leituras da absorbância foram realizadas após $30 \mathrm{~min}$ da mistura, no comprimento de onda de $595 \mathrm{~nm}$. A curva padrão foi preparada utilizando Trolox (500 a $\left.2000 \mu \mathrm{M} . \mathrm{L}^{-1}\right)$ nas mesmas condições das amostras. Os resultados da atividade antioxidante foram expressos em $\mu \mathrm{M}$ Trolox. $\mathrm{g}^{-1}$ extrato (atividade antioxidante equivalente ao Trolox).

\section{estudadas}

Predição das propriedades do biodiesel nas espécies de microalgas

A previsão das propriedades do biodiesel foi efetuada a partir das composições de ácidos graxos de cada espécie estudada, usando as várias equações descritas na literatura, de acordo com Nascimento et al. (2013). As previsões incluíram dados dos índices de instauração das cadeias de ácidos graxos (ADU), valor do iodo (IV), viscosidade cinemática a $40{ }^{\circ} \mathrm{C}(\rho)$, densidade $(\varphi)$, número de cetano (IC), ponto de entupimento do filtro a frio (PEFF), poder calorífico (HHV) e o fator de cadeia saturada longa (LCSF), como apresentadas abaixo:

$$
A D U=\sum M \times Y_{i} A D U=\sum M \times Y_{i} \quad \text { (Eq. 2) }
$$

Onde, ADU é o teor de insaturação do biodiesel de microalgas; M é a fração em massa do ácido graxo constituinte; Y é o número de duplas ligações de cada ácido graxo.

Viscosidade

$$
\rho=-0,6316 A D U+5,2065 \rho=-0,6316 A D U+5,2065 \quad \text { Eq. } 3
$$


Densidade

$\varphi=0,0055 A D U+0,8726 \varphi=0,0055 A D U+0,8726$

Eq. 4

Cetano

$I C=-6,6684 A D U+62,876 I C=-6,6684 A D U+62,876$

Eq. 5

Iodo

$I V=74,373 A D U+12,71 I V=74,373 A D U+12,71 \quad$ Eq. 6

Poder calorífico

$H H V=1,7601 A D U+38,534 H H V=1,7601 A D U+38,534 \quad$ Eq. 7

Fator de cadeia saturada longa

$L C S F=(0,1 \times C 16)+(0,5 \times C 18)+(1 \times C 20)+(1,5 \times C 22)+(2 \times C 24)$

$L C S F=(0,1 \times C 16)+(0,5 x C 18)+(1 \times C 20)+(1,5 x C 22)+(2 x C 24)$ Eq. 8

Ponto de entupimento de filtro a frio

$C F P P=(3,14 \times L C S F)-16,477 C F P P=(3,14 \times L C S F)-16,477$

Eq. 9

\section{Análise estatística}

Todos os dados obtidos para cada análise efetuada foram submetidos a tratamento estatístico utilizando o programa SISVAR, ao nível de 5\% de significância. As diferenças dos parâmetros analisados entre as espécies estudadas foram comparadas utilizando ANOVA e teste de Tukey.

\section{Resultados e discussão}

\section{Parâmetros cinéticos de crescimento}

Os experimentos tiveram a duração de 14 a 17 dias cada um. Os parâmetros de crescimento das espécies de microalgas investigadas mostraram valores de $k$ variando entre 0,47 divisões/dia em Pediastrum duplex a 1,39 em Coelastrum sp. Os maiores valores de biomassa seca foram registrados em Scenedesmus quadricauda, Scenedesmus obtusus, Pediastrum duplex e Microspora sp., sendo espécies essas que também apresentaram as maiores produtividades de biomassa (Tabela 2). Nenhuma das espécies com os maiores valores de $k$ apresentou os maiores rendimentos em biomassa, pelo contrário, as espécies mais produtivas apresentaram valores medianos de $k$, chamando atenção inclusive Pediastrum duplex que teve o menor valor de $k$ e um dos maiores rendimentos em biomassa. Valores de $k$ inferiores aos registrados nesta pesquisa foram encontrados em Chlorella vulgaris, Scenedesmus obliquus e Botryococcus braunii (Nascimento et al., 2013). 
Tabela 2. Parâmetros de crescimento das cepas de microalgas estudadas: $k=$ velocidade de crescimento; $\mathrm{RMax}=$ Cél. $\mathrm{mL}^{-1} \mathrm{x} 10^{5}$ ) $\mathrm{PB}=$ produtividade de biomassa. nd = não determinado.

\begin{tabular}{|l|l|l|c|c|c|}
\hline \multirow{2}{*}{ Cepa } & \multirow{2}{*}{ Identificação } & \multicolumn{2}{|c|}{ RMax. } & \multirow{2}{*}{$\begin{array}{c}\text { Biomassa } \\
\text { (mg.L }\end{array}$} & $\begin{array}{c}\text { Produtividade } \\
\text { de Biomassa } \\
\text { (mg.. }^{-1} \cdot \text { dia }^{-1} \text { ) }\end{array}$ \\
\hline D125WC & Scenedesmus quadricauda & $0,00 \times 00$ & $1,06 \pm 0,45$ & 392,00 & 32,67 \\
\hline D193WC & Coelastrum sp. & $6,49 \times 10^{5}$ & $1,39 \pm 0,75$ & 160,35 & 11,45 \\
\hline D209WC & Scenedesmus obtusus & $7,84 \times 10^{5}$ & $0,64 \pm 0,23$ & 354,98 & 20,35 \\
\hline D231WC & Pediastrum boryanum & $7,89 \times 10^{5}$ & $1,24 \pm 0,41$ & 107,97 & 8,30 \\
\hline D331WC & Synechocystis sp. 1 & $81,42 \times 10^{5}$ & $0,74 \pm 0,20$ & 201,30 & 7,49 \\
\hline D458WC & Selenastrum gracilis & $20,95 \times 10^{5}$ & $0,99 \pm 0,37$ & 165,72 & 12,74 \\
\hline D459WC & Microspora sp. & $16,77 \times 10^{5}$ & $1,08 \pm 0,46$ & 246,65 & 14,50 \\
\hline D464WC & Xanthonema sp. & $25,31 \times 10^{5}$ & $1,05 \pm 0,13$ & 167,75 & 11,98 \\
\hline D467WC & Actinastrum hantzschii & $63,21 \times 10^{5}$ & $0,98 \pm 0,50$ & 147,26 & 10,52 \\
\hline D511WC & Pediastrum duplex & $33,11 \times 10^{5}$ & $0,47 \pm 0,05$ & 297,35 & 21,23 \\
\hline
\end{tabular}

A maior produtividade de biomassa foi registrada em Scenedesmus quadricauda

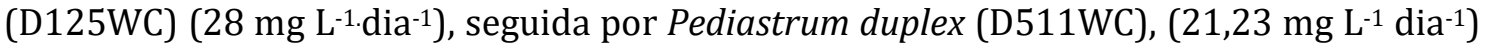
e Scenedesmus obtusus (D209WC) $\left(20,35 \mathrm{mg} \mathrm{L}^{-1} \mathrm{dia}^{-1}\right)$. 0 menor valor foi registrado em Synechocystis sp. 1 (D331WC), com 7,49 $\mathrm{mg} \mathrm{L}^{-1} \cdot \mathrm{dia}^{-1}$. As maiores densidades celulares foram registradas em Actinastrum hantzschii $\left(63,21 \times 10^{5}\right.$ células. $\left.\mathrm{mL}^{-1}\right)$ e em Pediastrum duplex $\left(33,11 \times 10^{5}\right.$ células. $\left.\mathrm{mL}^{-1}\right)$.

Os dados registrados na pesquisa mostram grande variabilidade no que concerne aos parâmetros de crescimento e produtividade de biomassa, devendo-se esperar, por conseguinte, variações interespecíficas na síntese de parâmetros bioquímicos de interesse à biotecnologia, sendo os teores desses compostos espécie-específicas. Mata et al. (2010) relatam vários fatores influenciando as respostas de crescimento das microalgas como a luz (qualidade e quantidade), temperatura, nutrientes, $\mathrm{O}_{2}, \mathrm{CO}_{2}, \mathrm{pH}$, salinidade, químicos tóxicos, e fatores bióticos como a presença de patógenos (bactérias, fungos e vírus), competição, e os fatores operacionais como a taxa de diluição, profundidade do cultivo, frequência de colheita, adição de compostos químicos, entre outros.

Calixto (2016) registrou valores máximos de biomassa chegando a $394 \mathrm{mg} \mathrm{L}^{-1} \mathrm{em}$ Synechococcus nidulans e $270 \mathrm{mg} . \mathrm{L}^{-1}$ Lagerheimia longiseta, portanto muito próximos aos registrados neste trabalho. A literatura indica alterações no rendimento em biomassa em várias microalgas de água doce e marinhas, como Scenedesmus sp., Nannochloropsis sp., Chlorella vulgaris, Selanastrum minutum, Coelastrum sp., Tetraselmis chui, relacionadas às condições de cultivo, particularmente a intensidade luminosa e o fotoperíodo (Wahidin et al., 2013; Khoeyi et al., 2012).

\section{Composição bioquímica da biomassa das espécies cultivadas}

Proteínas. Pediastrum duplex (D511WC) apresentou maior quantidade de proteína $(61,01 \%)$ de sua biomassa seca. Teores elevados também foram relatados nas espécies Microspora sp. (D459WC) Selenastrum gracilis (D458WC) (62,30\% e 51,10\%), enquanto nas demais espécies o teor variou entre 16,33 a 49,33\%. A maioria das espécies apresentou conteúdo proteico superior do que algumas fontes convencionais de alimentos, como frango (24\%), peixe (24\%), carne bovina $(22 \%)$ e amendoim $(26 \%)$ (Moorheadet al., 2011).

Algumas espécies de microalgas como Chlorella vulgaris, Spirulina maxima e Spirulina platensis apresentam teor protéico entre 51\%-58\%, 60\%-71\% e 46\%-63\%, respectivamente, sendo essas microalgas as mais usadas para a produção de proteína em 
escala industrial (Becker, 2007). Os resultados encontrados na presente pesquisa mostram que outras espécies podem ser igualmente aproveitadas para esta finalidade em função dos altos valores de proteínas que apresentam, ressaltando assim a importância de trabalho de bioprospecção na busca novas espécies que possam ser utilizadas na biotecnologia.

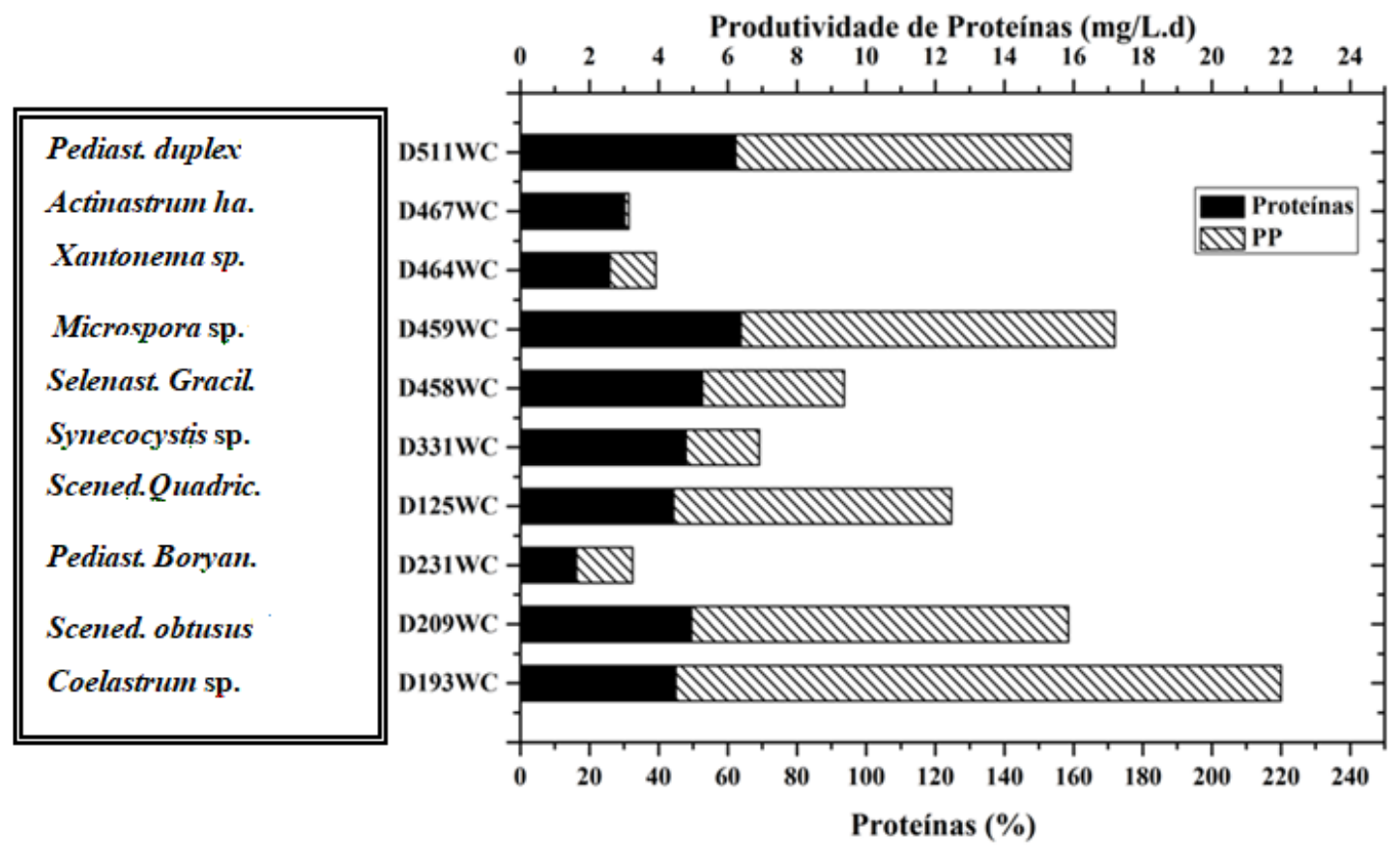

Figura 1. Teor de proteína e produtividade nas 10(dez) espécies de microalgas estudadas.

Carboidrato. Os valores de carboidrato variaram de 13,28\% em Scenedesmus quadricauda (D125WC) a 48,98\% em Xanthonema sp. (D464WC). Altos valores também foram registrados em Selenastrum gracilis (D458WC), com 44,88\%. Esses valores são atribuídos ao conteúdo de carboidrato que as espécies possuem e, nesse contexto, os valores encontrados são superiores ao referidos por Markou et. al. (2012) para Chlorella vulgaris, Spirulina platensis e Spirulina máxima, espécies amplamente usadas como alimento nutracêutico.

Diversas microalgas com elevado conteúdo de carboidrato são referidas na literatura como Porphyridium cruentum cujos valores oscilam entre $40 \%$ e $57 \%$ e Spirogyra sp. com valores entre 33\% e 64\% (Harun et al., 2010). Várias outras espécies de água doce da Hungria e da Romênia apresentaram valores similares aos registrados nesta pesquisa (entre 13,9 a 43,6\%), num estudo similar de bioprospecção de espécies de água doce efetuado por Selvarajan et al. (2015). Markou et al. (2012), no entanto, consideram ser possível incrementar a produtividade de carboidrato pela alteração nas condições de cultivo, quer seja através da deprivação de nutrientes como $\mathrm{N}, \mathrm{P}$ e $\mathrm{S}$, ou provocando estresses fóticos e otimizando o suprimento de nitratos, ou ainda, cultivando as espécies com adição de glicose, acetato e glicerol aos meios de cultivo. Tais alterações se tornam particularmente interessantes quando o propósito é aumentar a síntese desses compostos visando a produção de biocombustíveis e produtos biotecnológicos com base em todos os seus componentes naturais. 
No presente estudo nem todas as espécies com os maiores teores de carboidrato foram as que mostraram as maiores produtividades. Xanthonema sp. teve uma quantidade de carboidrato de $48,98 \%$, porém sua produtividade foi de apenas $5,65 \%$, em oposição à Scenedesmus obtusus, que teve um valor inferior de carboidrato $(36,37 \%)$, porém com maior produtividade $(7,31 \%)$, o que pode ser justificado pela variação na composição bioquímica de cada espécie, pois no decorrer dos cultivos, as algas apresentam muitas variações em sua composição bioquímica, porém, alterações exógenas como concentrações de salinidade por exemplo nos meios de cultivo podem influenciar na síntese de carboidratos, pois a diminuição da fonte de nitrogênio e o aumento da concentração de cloreto de sódio acarretam no aumento do acúmulo de carboidratos em suas células.

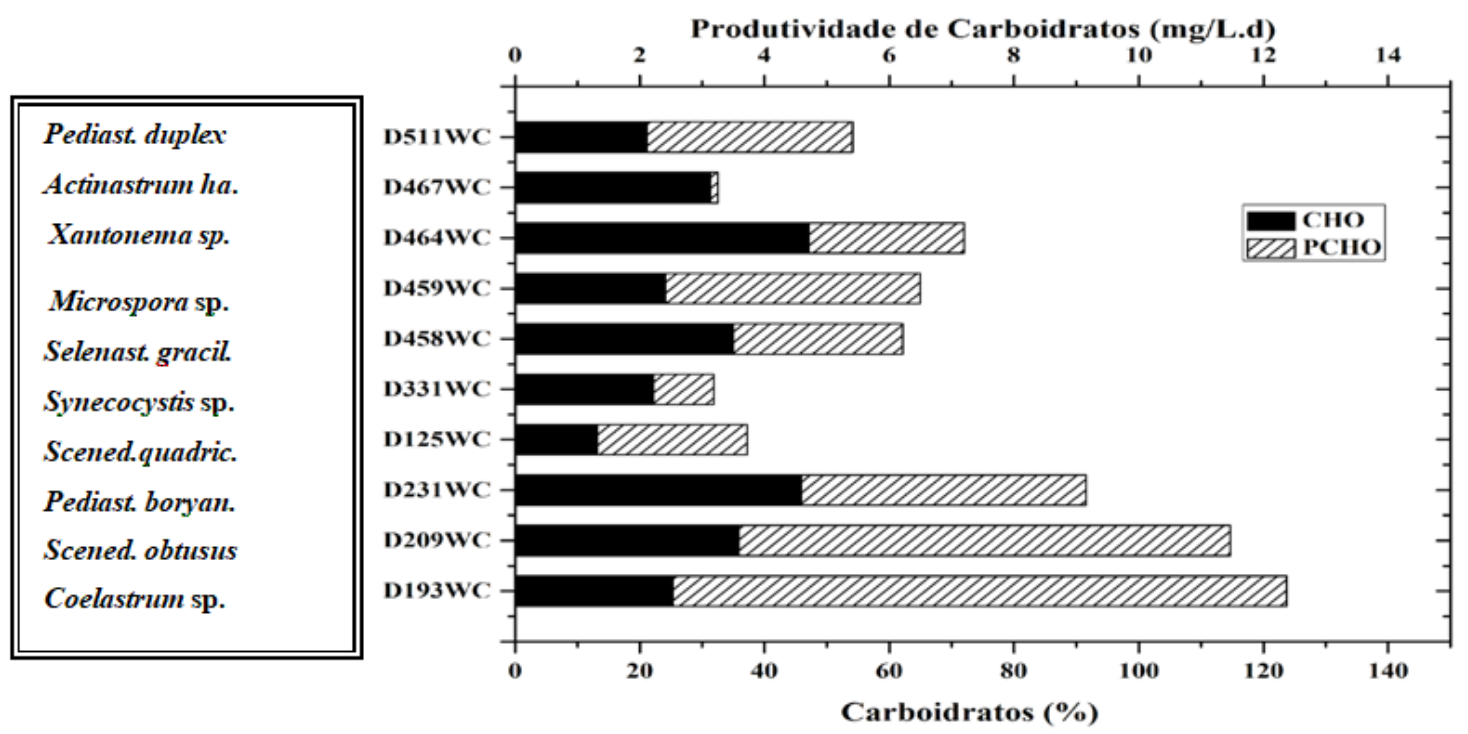

Figura 2. Teor de carboidrato e produtividade nas 10(dez) espécies de microalgas estudadas.

Os maiores valores de lipídeos foram encontrados nas clorofíceas Selenastrum gracilis (D458WC), Pediastrum boryanum (D231WC), Coelastrum sp.,(D193WC) seguidas pela cianobactéria Synechocystis sp. (D331WC), todas com teores acima de 20\% (23,65\%, $23,07 \%, 22,20 \%$ e $21,35 \%$, respectivamente), evidenciando que os teores lipídicos variam conforme a espécie. Araújo et al. (2011) também avaliaram a produção de biomassa e óleo de 10 espécies. 0 resultado da pesquisa apontou a Nannochloropsis oculata como uma das espécies mais resistentes e de maior produção de biomassa e óleo, (37\%-60\%). outros autores, como Lim et al. (2012), também identificaram a Nannochloropsis oculata como melhores produtoras de lipídios tanto em ambientes fechados como abertos. Desta forma, observa-se que as microalgas têm características bem atrativas do ponto de vista de produção de lipídios entretanto, o êxito biotecnológico destas depende da escolha de espécies com propriedades relevantes e com fácil cultivo, para alcançar uma alta produção de bio-óleo com um custo competitivo com o mercado de biocombustíveis. 


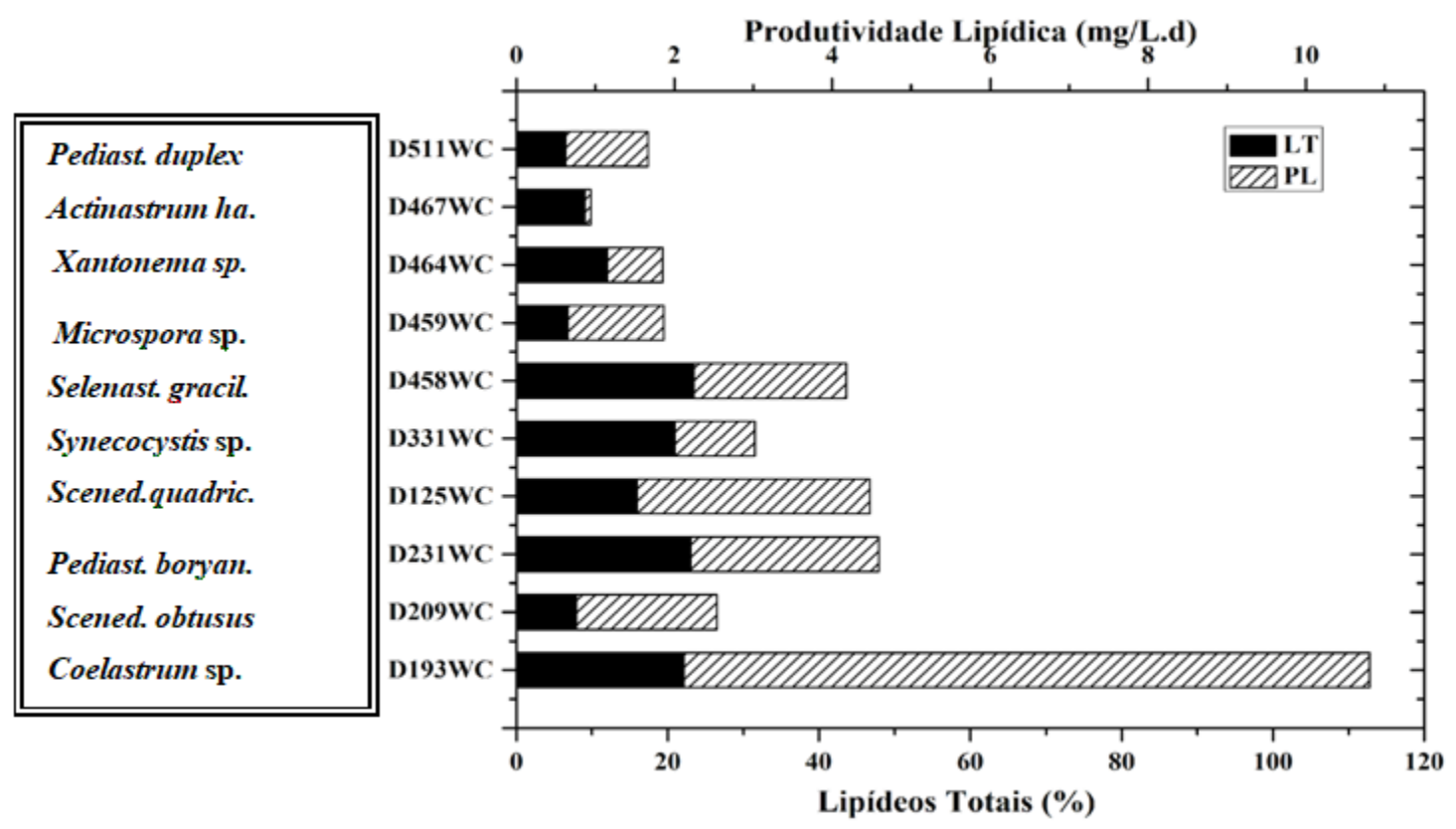

Figura 3. Teor de lipídeos e produtividade lipídica nas 10 (dez) espécies de microalgas estudadas.

Valor de 25,6\% foi registrado por Servel et al. (1994) em Isochrysis galbana. Valores superiores foram relatados por Mata et al. (2010), chegando até $57 \% \mathrm{em}$ Phaeodactylum tricornutum, 40\% em Isochrysis galbana, 58\% em Chlorella vulgaris, 33\% em Isochrysis e 33,6\% em Chaetoceros muelleri. Embora esses valores sejam substancialmente mais elevados do que os que foram registrados nas espécies estudadas há que se ressaltar que ainda assim os nossos valores são superiores em algumas espécies que comumente são registrados na soja, que em geral ficam em torno de $24 \%$, uma das principais oleaginosas usadas para a produção de biodiesel (Silva et al., 2006).

Uma das questões a serem levantadas no tocante às análises de lipídios em microalgas diz respeito ao método de extração visto que este pode influenciar no teor de material lipídico extraído e, consequentemente, na produtividade lipídica (Jones et al., 2012; Araújo et al., 2013; Silva et al., 2014). 0 melhor método é aquele que propicia maior acessibilidade ao conteúdo lipídico estando associado, portanto, com o grau de dificuldade encontrado na ruptura da parede celular. No presente caso foi usado ultrassom para rompimento da parede celular. Tal procedimento é eficiente, particularmente para cianobactérias (Silva et al., 2014), porém para clorofíceas tem-se demonstrado que associação de ultrassom com autoclave ou apenas autoclave são mais eficientes (Lee, 2010). Desse modo ressalta-se que teores mais elevados de lipídios podem ser obtidos, adotando-se outros procedimentos para o rompimento da parede celular.

Usualmente considera-se que as microalgas eucarióticas possuem maior teor lipídico do que as procarióticas (Williams e Laurens, 2010), e as clorofíceas, em particular, são relatadas como um dos grupos que apresentam os mais elevados níveis de lipídios neutros (Chen et al., 2011). Neste estudo constatou-se, que a cianobactéria Synechocystis sp. 1 (cepa D331WC) apresentou um equivalente de lipídios em relação aos maiores valores registrados nas clorofíceas. Ressalta-se, ainda, que a biossíntese de lipídeos está associada a diversos fatores (Richmond, 2004), dentre os quais se relacionam às condições de cultivo, o tipo de cultivo, as concentrações de nutrientes, o estágio da fase de crescimento em que a cultura se encontra, e fatores ambientais de estresse que podem 
alterar o metabolismo celular, como deprivação de nitrogênio ou choques térmicos, fóticos e luminosos.

A depleção de nitrogênio, por exemplo, força o metabolismo das microalgas a diminuírem os teores de proteínas ou peptídeos, aumentando em contrapartida o percentual de compostos ricos em energia como carboidratos e lipídios (Ho et al., 2014).

Diversos autores também relataram ocorrer um aumento significativo na biomassa, nos carboidratos e no teor de lipídios de algumas espécies de microalgas sob condições mixotróficas e heterotróficas quando comparado com a condição fototrófica (Giovanardi et al., 2013; Liang, 2013; Liu et al., 2014; Rattanapoltee e Kaewkannetra, 2014) fato este que abre novas perspectivas acerca da aplicação dos cultivos de microalgas em processos biotecnológicos

\section{Perfil de ésteres metílicos de ácidos graxos}

A maioria dos lipídios presentes nas microalgas contém ácidos graxos que possuem de 8 a 22 carbonos e podem ser saturados ou insaturados (Medina et al., 1998; Halim et al., 2012). Segundo Nascimento et al. (2013) a composição e o número de insaturações dos ácidos graxos influenciam diretamente as características finais do biodiesel. Branco et al. (2014) afirmam que o que pode levar à produção de um biodiesel de qualidade é a composição em ácidos graxos do óleo da microalga e o perfil de ésteres que devem assemelhar-se à composição em ácidos graxos do óleo de soja, principal matéria-prima hoje utilizada para a produção de biodiesel no Brasil.

De acordo com os dados da Tabela 3, os ácidos graxos comumente encontrados em todas as microalgas estudadas foram láurico (C12:0), mirístico (C14:0), pentadecílico (C15:0), pentadecanóico (C15:1), palmítico (C16:0), palmitoleico (C16:1 cis9), heptadecenoico (C17:1), esteárico (C18:0), elaídico (C18:1) e linoleico (C18:2 cis9, cis12). Entre esses se destaca a presença em grande quantidade do ácido graxo palmítico cuja participação percentual variou de 1,13\% em Actinastrum hantzschii (D467WC) a 39,12\% em Scenedesmus quadricauda (D125WC). Teores predominantes deste ácido graxo também foram encontrados por Sassi (2016) e por Ambrozova et al. (2014).

Outro ácido presente em todas as espécies estudadas e que apresenta dominância em oleaginosas de acordo com a literatura, é o esteárico (C18:0), utilizado em agentes de consistência como sabões, detergentes, velas, cremes e loções. Este ácido graxo foi encontrado em pequena quantidade, com valores entre 0,18\% em Actinastrum hantzschii (D467WC) e 5,12\% em Scenedesmus quadricauda (D125WC).

A composição de ácidos graxos das microalgas Coelastrum sp. (D193WC), Pediastrum boryanum (D231WC), e Pediastrum duplex (D511WC) é caracterizada por elevados teores de ácidos como o palmítico (C16:0), vacênico (18:1) e gadoléico (C20:1), seguidos pelos ácidos elaídico (C18:1) e linoléico (C18:2 cis9, cis12). Os ácidos insaturados são encontrados em teores variáveis nas espécies, ressaltando-se os valores para o vacênico que é encontrado em até 25\% em Pediastrum duplex (D511WC).

As insaturações tornam as microalgas propensas aos processos oxidativos do óleo e do biodiesel produzido, pois quanto maior o índice de insaturações dos ácidos graxos, menor sua estabilidade oxidativa, conseqüentemente o material é degradado com maior facilidade. De acordo com Oetterer (2006), os ácidos linoléico e linolênico (com duas e três duplas ligações, respectivamente) podem ser oxidados a uma velocidade de 64 a 100 vezes maior que o ácido oléico (com uma dupla ligação). A presença desses ácidos também foi identificada em microalgas dos gêneros Amphora, Chaetoceros, Chlorella, Dunaliella e Isochrysis (Knothe, 2011). 
Tabela 3. Composição de ácidos graxos por grau de saturação das dez espécies de microalgas estudadas.

\begin{tabular}{|c|c|c|c|c|c|c|c|c|c|c|}
\hline \multirow{2}{*}{$\begin{array}{l}\text { \% Ácidos } \\
\text { graxos }\end{array}$} & \multicolumn{10}{|c|}{ Espécies } \\
\hline & D125WC & D193WC & D209WC & D231WC & D331WC & D458WC & D459WC & D464WC & D467WC & D511WC \\
\hline C8:0 & & & & 0,39 & & & & & 0,3 & \\
\hline C10:0 & & & & 0,53 & & & & & 0,27 & \\
\hline C11:0 & & & 0,58 & 0,4 & & & & & 1,48 & \\
\hline C12:0 & 1,13 & 0,99 & 1,7 & 1,39 & 1,92 & 1,45 & 1,75 & 0,6 & 1,09 & 1,08 \\
\hline C13:0 & 1,29 & 0,69 & 0,83 & 0,86 & 2,2 & 0,69 & 1,18 & & 0,19 & 0,29 \\
\hline C14:0 & 3,44 & 0,41 & 0,21 & 1,43 & 0,45 & 0,67 & 0,68 & 2,1 & 0,35 & 0,86 \\
\hline C14:1 & 2,10 & 0,34 & 0,31 & 0,24 & 0,7 & & 0,42 & 0,79 & 1,97 & \\
\hline C15:0 & 1,16 & 0,88 & 1,16 & 0,77 & 1,48 & 0,73 & 1,04 & & 3,22 & 0,38 \\
\hline C15:1 & & 3,2 & 6,3 & 2,3 & 2,2 & 5,71 & 4,73 & 0,86 & 13,87 & 0,3 \\
\hline C16:0 & 39,12 & 24,51 & 28,47 & 33,83 & 28,91 & 20,4 & 20,55 & 29,59 & 1,13 & 27,79 \\
\hline C16:1 & 2,74 & 0,72 & 0,6 & 0,31 & 1,06 & 0,72 & 0,71 & 1,18 & & 0,23 \\
\hline C17:0 & & 0,46 & 0,21 & 0,73 & 1,5 & 0,31 & 0,5 & 0,9 & 3,71 & 0,46 \\
\hline C17:1 & & 0,23 & 1,24 & 0,85 & 1,27 & 1,09 & 0,83 & 0,8 & 1,18 & 0,41 \\
\hline C18:0 & 5,12 & 3,18 & 1,58 & 2,37 & 1,94 & 3,34 & 3,11 & 3,55 & 0,18 & 3,15 \\
\hline C18:1n9t & 6,39 & 1,55 & 1,04 & 2,09 & 0,45 & 0,34 & 0,74 & 1,85 & 5,21 & 1,04 \\
\hline C18:1n9c & 15,85 & 18,3 & 6,7 & 17,91 & 9,81 & 9,17 & 7,88 & 10,14 & 9,17 & 25,63 \\
\hline C18:2n6t & & 3,4 & 4,07 & 3,54 & 2,48 & 9,33 & 7,42 & 0,95 & 6,68 & 5,23 \\
\hline C18:2n6c & 9,89 & 3,35 & 4,33 & 7,93 & 3,99 & 5,86 & 5,03 & 19,17 & & 7,53 \\
\hline C18:3n6 & & & & & & & & 1,28 & & 0,21 \\
\hline C18:3n3 & 11,77 & & & & & & & 13,96 & 2,27 & \\
\hline C20:0 & & & & & 0,53 & & & 2,07 & & 1,18 \\
\hline C20:1 & & 16,59 & 19,27 & 12,88 & 0,53 & 18,54 & 15,02 & & 25 & 15,19 \\
\hline C20:2 & & 1,24 & 1,42 & 1,17 & 0,42 & 1 & 0,72 & & 2,23 & 1,13 \\
\hline C20:3n3 & & & & & & & & 1,4 & 0,3 & \\
\hline C20:3n6 & & & & & 0,48 & & & 1,79 & & \\
\hline C20:4n6 & & & & & & & & 1,41 & & \\
\hline C20:5n3 & & & & & & 0,46 & & & & \\
\hline C22:0 & & & & 0,82 & 1,04 & & & 2,1 & & 0,34 \\
\hline C22:1n9 & & & & & & & & 1,87 & & \\
\hline C22:6 n-3 & & & & & & & & 1,64 & & \\
\hline AGS & 51,26 & 35,61 & 43,19 & 47,22 & 45,2 & 35,11 & 35,5 & 44,54 & 28,94 & 36,47 \\
\hline AGMI & 27,08 & 36,44 & 27,01 & 32,88 & 10,79 & 28,05 & 23,64 & 11,99 & 39,38 & 41,86 \\
\hline AGPI & 21,66 & 7,99 & 9,82 & 12,64 & 7,37 & 16,65 & 13,17 & 41,6 & 11,48 & 14,1 \\
\hline AGMI/AGS & 0,58 & 1,02 & 0,63 & 0,70 & 0,24 & 0,80 & 0,67 & 0,27 & 1,36 & 1,15 \\
\hline AGPI/AGS & 0,42 & 0,22 & 0,23 & 0,27 & 0,16 & 0,47 & 0,37 & 0,93 & 0,40 & 0,39 \\
\hline
\end{tabular}

C8:0 = Caprílico; C10:0 = Cáprico; C11:0 = Undecílico; C12:0 = Láurico; C13:0 = Tridecílico; C14:0 = Mirístico; C14:1 = Miristoleico; C15:0 = Pentadecilico; C15:1 = Pentadecenoico; C16:0 = Palmítico; C16:1 = Palmitoleico; C16:1 = Palmitoleico; C17:0 = Margárico; C17:1 = Heptadecaenoico; C18:0 = Esteárico; C18:1 $\omega-9$ = Oléico; C18:1 = Vacênico; C18:1 = Elaídico; C18:2 $\omega-6$ = Linoleico (AL); C18:2 = Linolelaídico; C18:3 $\omega-3$ = Linolênico (ALA); C20:0 = Eicosanoico; C20:1 = Gadolêico; C20:2 Eicosadienoico; C20:3 = Homo $-\gamma-$ linolênico; C22:0 = Behênico; C20:5 = Eicosapentanoico (EPA); C22:6 = Docosahecanoico (DHA). AGS= Ácidos graxos saturados, AGMI = Ádicos graxos monoinsaturados, AGPI= Ácidos graxos polinsaturados.

Em relação ao grau de saturação dos ácidos graxos presentes nas 10 espécies analisadas (Figura 4) observou-se uma concentração maior de ácidos graxos saturados (AGS) e monoinsaturados (AGMI) e um menor percentual de ácidos graxos poliinsaturados (AGI).

Ésteres alquílicos de ácidos graxos saturados (láurico, palmítico, esteárico) estão presentes em todas as 10 espécies analisadas, sendo este um ponto importante nesse estudo, pois, de acordo com os parâmetros estabelecidos para produção de biodiesel 
utilizando microalgas como matéria prima, busca-se selecionar espécies de microalgas que apresentem alta produtividade em ácidos graxos, os quais devem ser preferencialmente uma mistura de ácidos saturados e monoinsaturados (Calixto, 2016).

De acordo com Menezes et al. (2013) essas espécies deverão apresentar reduzido teor de ácidos com duas ou mais duplas ligações, o que levaria à obtenção de biodiesel com alta estabilidade oxidativa e adequada propriedade de congelamento.

Em termos percentuais de ácidos graxos saturados totais presentes nas espécies estudadas, observaram-se índices maiores para Scenedesmus quadricauda (D125WC), (51,26\%), seguido por Pediastrum boryanum D231WC (47,22\%) (Figura 4). Em meio a esses AGS, o ácido palmítico merece destaque por estar presente em todas as espécies com teores variando de 1,13\% a 33,83\%. Altos teores desse ácido, associado a baixos teores de di, tri e poli-insaturados favorecem algumas das propriedades físicas do biodiesel, tais como as de ponto de entupimento e viscosidade.

Ácido palmítico ou ácido hexadecanóico é um dos ácidos graxos saturados mais comuns, encontrados em animais e plantas. É o principal componente do óleo de palma com composição em AGS (palmítico 44\% e esteárico 4\%) AGI (oléico 40\% e linoléico 10\%). De acordo com Costa (2016), A grande quantidade de ácidos graxos saturados (ácido palmítico) torna o óleo de palma viável em aplicações que levam à obtenção de biocombustíveis semelhantes aos derivados de petróleo, tais como gasolina e querosene. Zambiazi et al. (2007) e Calixto (2016) afirmam que esse ácido pode ser utilizado como surfactante em produtos de limpeza e na produção de cosméticos.

Os ácidos graxos monoinsaturados presentes em todas as microalgas foram os ácidos, palmitoleico (C16:1) e elaídico (C18:1). 0 ácido oléico (C18:1 $\dot{\omega}-9)$ não foi encontrado, apenas nas espécies Xanthonema sp. (D464WC), que juntamente a espécie Scenedesmus quadricauda (D125WC) também não expressou o MUFA gadoléico (C20:1).

\begin{tabular}{||l||}
\hline D125WC Scened.quadric. \\
D193WC Coelastrum sp. \\
D209WC Scened. obtusus \\
D231WC Pediast. boryanum \\
D331WC Synecocystis sp. \\
D458WC Selenast. gracillis \\
D459WC Microspora sp. \\
D464WC Xantonema sp. \\
D467WC Actinastrum hantz. \\
D511WC Pediast. duplex \\
\hline \hline
\end{tabular}

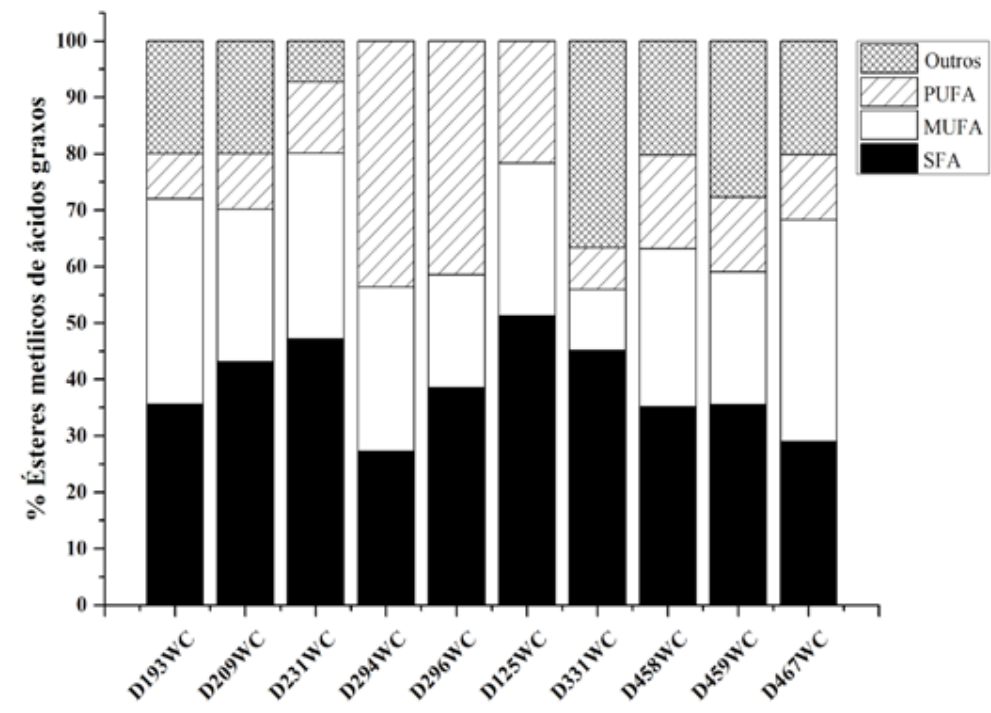

Figura 4. Percentual de ácidos graxos por saturação presentes nas microalgas estudadas.

Todas as microalgas analisadas apresentaram em sua composição índices do ácido graxo poliinsaturado linoléico (C: 18:2ف่6), merecendo especial atenção a Xanthonema sp. (D464WC), cujo teor (52,7\%) foi muito superior aos das demais espécies estudadas, evidenciando que esta espécie tem um alto potencial para uso na indústria alimentícia. 
Os ácidos graxos poli-insaturados por possuírem um número de cetano geralmente baixo, diminuem a qualidade de combustão, propiciam o processo oxidativo do óleo e, consequentemente, do biodiesel produzido, o que os tornam inconvenientes para uso na produção do biodiesel. De acordo com Chisty (2007) a maioria dos óleos das microalgas é rico em ácidos graxos poliinsaturados com quatro ou mais ligações duplas, porém o problema associado com este grau de poliinsaturação é que estes ácidos graxos são sensíveis à oxidação durante o armazenamento, reduzindo assim sua aceitabilidade para uso em biodiesel.

De acordo com Knothe (2013), Menezes et al. (2013) e Rawat (2012), a propriedade de índice de cetano, que mede a qualidade da combustão, está relacionada com a velocidade de ignição. Um alto índice de cetano indica bom funcionamento do motor, com minimização da quantidade de poluentes emitidos. Esta propriedade é influenciada pelo grau de saturação e comprimento da cadeia carbônica.

Avaliando os parâmetros estabelecidos pela norma EN 14214, o limite máximo para microalgas, estabelecido para o teor de ácidos tri-insaturados é de $12 \%$, e de $1 \%$ para o teor máximo de ácidos graxos com mais de três duplas ligações (PUFA). Levando em consideração essas determinações, a proporção no presente estudo apresentou-se dentro das normas estabelecidas com exceção da espécie Xanthonema sp. (D464WC) que apresentou teor de 15,37\% em sua composição para tri-insaturados.

\section{Predição das propriedades do biodiesel nas espécies estudadas}

De acordo com Georgianna et al. (2012), as propriedades combustíveis mais importantes para avaliar o potencial do biodiesel como substituto do diesel são viscosidade cinemática, número de cetano, densidade, propriedades de fluxo a frio, estabilidade oxidativa, qualidade de ignição e calor de combustão. A Tabela 4 mostra os resultados obtidos para a predição das propriedades combustíveis das 10 espécies selecionadas para este estudo. A substituição do diesel fóssil pelo biodiesel proveniente do óleo de microalgas é fortemente dependente do cumprimento das especificações dos parâmetros de qualidade combustíveis, normatizados por alguns órgãos reguladores (Rawat et al., 2013).

Tabela 4. Predição das propriedades do biodiesel das microalgas estudadas.

\begin{tabular}{|c|c|c|c|c|c|c|c|c|}
\hline Microalgas & ADU & $\begin{array}{c}\text { Viscosidade } \\
40^{\circ} \mathrm{C} \\
\left(\mathrm{mm}^{2} \mathrm{~s}^{-1}\right)\end{array}$ & $\begin{array}{l}\text { Densidade } \\
\text { (kg/L) }\end{array}$ & $\begin{array}{c}\text { Número } \\
\text { de } \\
\text { Cetano }\end{array}$ & $\begin{array}{l}\text { Índice de Iodo } \\
\text { (g Iodo/100 g) }\end{array}$ & $\begin{array}{c}\text { HV } \\
(\mathrm{MJ} / \mathrm{kg})\end{array}$ & LCSF & $\begin{array}{l}\text { PEFF } \\
\left({ }^{\circ} \mathrm{C}\right)\end{array}$ \\
\hline D125WC & 0,82 & 4,688 & 0,877 & 57,40 & 73,82 & 39,98 & 6,472 & 3,8560 \\
\hline D193WC & 0,53 & 4,872 & 0,876 & 59,34 & 52,13 & 39,47 & 4,041 & $-3,78139$ \\
\hline D209WC & 0,51 & 4,885 & 0,875 & 59,48 & 50,64 & 39,43 & 3,637 & $-5,05064$ \\
\hline D231WC & 0,58 & 4,840 & 0,876 & 59,01 & 55,85 & 39,55 & 2,753 & $-7,8279$ \\
\hline D331WC & 0,29 & 5,023 & 0,874 & 60,94 & 34,28 & 39,04 & 1,789 & $-10,8565$ \\
\hline D458WC & 1,18 & 4,462 & 0,879 & 55,01 & 100,47 & 40,61 & 1,874 & $-10,5895$ \\
\hline D459WC & 0,49 & 4,897 & 0,875 & 59,61 & 49,15 & 39,40 & 1,76 & $-10,9476$ \\
\hline D464WC & 1,23 & 4,430 & 0,879 & 54,67 & 104,19 & 40,70 & 4,308 & $-2,94256$ \\
\hline D467WC & 0,67 & 4,784 & 0,876 & 58,41 & 62,54 & 39,71 & 2,999 & $-7,05504$ \\
\hline D511WC & 0,66 & 4,790 & 0,876 & 58,47 & 61,80 & 39,70 & 3,543 & $-5,34596$ \\
\hline
\end{tabular}

HHV = poder calorífico; LCSF = baixa produção de carbono; PEFF = Ponto de entupimento de filtro a frio.

Estes padrões de qualidade para o biodiesel requerem um número mínimo de cetano de 47 pela norma americana (ASTM D6751) e 51 pela norma europeia (EN 14214). 
No presente trabalho, verificou-se conformidade nos valores de cetano calculado para as espécies, que variaram de 55 a 60, com as normas supracitadas. Quanto maior o NC, melhores são as propriedades de ignição do biodiesel, menores são as emissões de óxido nitroso $\left(\mathrm{N}_{2} \mathrm{O}\right)$, e maior é a facilidade de partida do motor (Ramos et al.,2009).

0 índice de iodo é um método convencional utilizado para determinar o grau de insaturação de óleos, gorduras e biodiesel, como indicativo de sua propensão aos processos oxidativos que originam a formação de depósitos e problemas no motor (Calixto, 2016). Todas as espécies de microalgas estudadas apresentaram valores inferiores ao determinado pelos padrões europeus de biodiesel (máximo de $120 \mathrm{mg}$ $\mathrm{I}_{2} / 100 \mathrm{~g}$ ), variando entre 34 a $104 \mathrm{mg} \mathrm{I}_{2} / 100 \mathrm{~g}$, bem como ao de oleaginosas potenciais da matriz de produção de biodiesel, como a soja e girassol que apresentam respectivamente 128 e 132,6 mg I $2 / 100 \mathrm{~g}$ (Ferrari e Souza, 2009). Elevados valores de iodo no biodiesel podem resultar na polimerização de glicéridos e deposição de lubrificante no motor (Francisco et al., 2010).

O ponto de congelamento dos ácidos graxos saturados é sempre maior que o dos ácidos graxos insaturados. Quando o biodiesel contém quantidades significativas de moléculas de ésteres saturados, principalmente de cadeia longa, a cristalização pode ocorrer em baixas temperaturas, o que resulta em fracas propriedades de fluxo, pois ocorre restrição à circulação do combustível pelos filtros e sistema de alimentação durante a partida (Francisco et al., 2010). A Agência Nacional do Petróleo, Gás Natural e Biocombustíveis (ANP) propõe valores limitantes para este parâmetro por regiões brasileiras, bem como por períodos sazonais, determinando valores máximos que variam de $5{ }^{\circ} \mathrm{C}$ a $19{ }^{\circ} \mathrm{C}$. Entretanto, vale ressaltar que as propriedades de fluxo dependem das condições da região na qual o combustível será utilizado, bem como o uso de aditivos anticongelantes vem sendo estudado para viabilizar o uso de algumas matrizes que não atendem a essa especificação.

Outro parâmetro crítico para o biodiesel é a viscosidade cinemática por afetar os sistemas de bombeamento e injeção em motores, podendo comprometer ainda a atomização do combustível. Todas as microalgas exibiram valores de viscosidade dentro dos limites estabelecidos pela resolução ANP $\left(3\right.$ a $\left.6 \mathrm{~mm}^{2} \mathrm{~s}^{-1}\right)$, com valores que variam de $4,430 \mathrm{~mm}^{2} \mathrm{~s}^{-1}$ para a espécie Xanthonema sp. (D464WC) a 5,023 $\mathrm{mm}^{2} \mathrm{~s}^{-1}$ para Synechocystis sp. 1 (cepa D331WC).

No que diz respeito à densidade, as dez espécies de microalgas atenderam as especificações $\left(0,85-0,90 \mathrm{~kg} \mathrm{~L}^{-1}\right)$ com valores praticamente constantes $\left(0,87 \mathrm{~kg} \mathrm{~L}^{-1}\right)$. De acordo com Alptekin e Canakci, (2008) a densidade relaciona-se diretamente ao poder calorífico do biodiesel, dessa forma também não foram expressas grandes diferenciações nos valores referentes ao poder calorífico para as microalgas em estudo. Expressaram-se valores de 39,04 a 40,70 MJ/kg, valores superiores ao óleo de soja $(37,50 \mathrm{MJ} / \mathrm{kg})$ definido por Costa Neto et al. (2000).

\section{Teor de fenólicos extraíveis totais}

Determinou-se o teor de fenólicos totais das microalgas pesquisadas com o objetivo de identificar uma fonte natural de compostos fenólicos nestas espécies. A variação entre os teores de fenólicos entre as espécies em seus extratos metanólicos, considerando as diferenças estatísticas entre elas, mostrou que o maior valor de fenólicos totais foi para a espécie Pediastrum boryanum (D231WC) (48,61 mg EAG g-1) e menor valor foi para Microspora sp. (D459WC) (13,09 mg EAG $\mathrm{g}^{-1}$ ). Os teores de fenólicos encontrados nas microalgas estudadas nesta pesquisa encontram-se acima dos relatados por Safafar et al. (2015) que encontrou para extrato metanólico da microalga Desmodesmus sp., maior teor de fenólicos de 7,72 mg EAG g-1.

Choochote et al. (2014), usando o etanol e o hexano como solventes extratores, obtiveram teores maiores de fenólicos, para estes solventes, seguindo a ordem de citação 
dos solventes usados. Essas diferenças podem ser atribuídas às diferenças de polaridade dos compostos fenólicos. E, ainda que a maioria dos compostos fenólicos apresentam natureza geralmente polar, a concentração dos fenólicos em cada espécie pode ser responsável por esses resultados.

\section{Determinação da atividade antioxidante (in vitro)}

Potencial antioxidante de redução do ferro (FRAP). Para a análise que avalia o potencial antioxidante de redução do ferro (FRAP) (Tabela 5), as melhores capacidades antioxidantes de redução de ferro foram obtidas para as microalgas Scenedesmus quadricauda (D125WC) $\left(21783,66 \mu \mathrm{mol} \mathrm{Tx}^{-1}\right.$ ), seguido de Pediastrum boryanum (D231WC) $\left(48,61 \mu \mathrm{mol} \mathrm{Tx} \mathrm{g}^{-1}\right)$. Os menores resultados foram encontrados por Microspora sp. (D459WC) $(13,09 \mu \mathrm{mol} \mathrm{Tx} \mathrm{g-1)} \mathrm{e} \mathrm{Selenastrum} \mathrm{gracilis} \mathrm{(D458WC)}(16,94 \mu \mathrm{mol} \mathrm{Tx} \mathrm{g-1})$. Outros autores encontraram valores superiores aos encontrados nesta pesquisa, atribuindo as microalgas Chlorella vulgaris, Haematococcus pluvialis, Nannochloropsis sp. e Tetraselmis sp, atividade antioxidante alta, quando avaliada pelo ensaio FRAP, com valores acima de $40 \mu \mathrm{mol} \mathrm{Tx} \mathrm{g-1}$ de biomassa (Goiris et al., 2012; Hajimahmoodi et al., 2010), relataram valores que refletem capacidade antioxidante elevada para as espécies

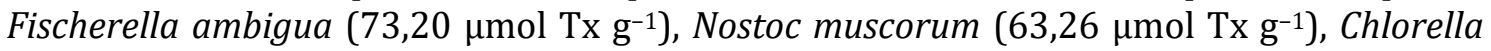
vulgaris $\left(58,21 \mu \mathrm{mol} \mathrm{Tx} \mathrm{g}^{-1}\right)$ e Anabaena cylindrica $\left(54,79 \mu \mathrm{mol} \mathrm{Tx}^{-1}\right)$. Este ensaio quantifica os antioxidantes que promovem a transferência de um elétron, contudo não é possível detectar os compostos que suprimem os radicais por transferência de um átomo de hidrogênio. Assim, são detectados principalmente atividade antioxidante de polifenóis (Chatterjee e Bhattacharjee, 2013).

Tabela 5. Atividade antioxidante pelos ensaios FRAP, ABTS, DPPH E Fenólicos extraíveis totais das dez espécies de microalgas estudadas.

\begin{tabular}{|c|c|c|c|c|c|}
\hline Cepa & Identificação & $\begin{array}{c}\text { FRAP } \\
\left(\mu \text { molTx }-^{1}\right)\end{array}$ & $\begin{array}{c}\text { ABTS } \\
\left(\mu \mathrm{molTx} / \mathrm{g}-{ }^{1}\right)\end{array}$ & $\begin{array}{c}\text { DPPH } \\
(\mu \mathrm{mol} \mathrm{Tx} / \mathrm{g})\end{array}$ & $\begin{array}{c}\text { Fenólicos } \\
\left(\text { mgEAG g- }^{-1}\right)\end{array}$ \\
\hline D125WC & Scenedesmus quadricauda & $21,78^{a} \pm 0,18$ & 0 & $116,70^{a} \pm 0,33$ & $21783,66^{a} \pm 0,33$ \\
\hline D193WC & Coelastrum sp. & $48,61^{\mathrm{b}} \pm 0,15$ & $3,17^{c} \pm 0,31$ & $32,86^{\mathrm{e}} \pm 3,35$ & $16,06^{\mathrm{cd}} \pm 0,25$ \\
\hline D209WC & Scenedesmus obtusus & $45,97 \mathrm{bc} \pm 0,42$ & $19,41^{\mathrm{a}} \pm 0,36$ & $65,38^{b c} \pm 3,83$ & $27,04 \mathrm{bcd} \pm 0,54$ \\
\hline D231WC & Pediastrum boryanum & $35,09 \mathrm{bcd} \pm 0,29$ & $0,16^{\mathrm{e}} \pm 0,04$ & $44,07 \mathrm{~d} \pm 4,39$ & $48,61^{\mathrm{b}} \pm 0,94$ \\
\hline D331WC & Synechocysti s sp. 1 & $27,04^{\mathrm{bcd}} \pm 0,57$ & $19,41^{\mathrm{a}} \pm 1,07$ & $57,50^{c} \pm 3,19$ & $45,97 \mathrm{bc}_{ \pm 0} 0,40$ \\
\hline D458WC & Selenastrum gracilis & $24,30^{\mathrm{bcd}} \pm 0,10$ & $1,51^{\mathrm{d}} \pm 0,10$ & $16,65^{f} \pm 2,33$ & $16,94 \mathrm{~cd} \pm 0,38$ \\
\hline D459WC & Microspora sp. & $18,09 \mathrm{bcd} \pm 0,10$ & $5,37 \mathrm{~b} \pm 0,18$ & $9,77^{f} \pm 1,67$ & $13,09 \mathrm{~d} \pm 0,41$ \\
\hline D464WC & Xanthonema sp. & $16,94^{\mathrm{cd}} \pm 0,58$ & $18,46^{\mathrm{a}} \pm 0,17$ & $40,40^{\text {de }} \pm 2,71$ & $24,30^{\text {bcd }} \pm 0,33$ \\
\hline D467WC & Actinastrum hantzschii & $16,06^{\mathrm{cd}} \pm 0,14$ & $2,57 \mathrm{~cd} \pm 0,22$ & $17,98^{\mathrm{f}} \pm 3,84$ & $18,09 \mathrm{bcd} \pm 0,57$ \\
\hline D511WC & Pediastrum duplex & $13,09 \mathrm{~d} \pm 0,60$ & $6,14 \mathrm{~b} \pm 0,22$ & $67,04 \mathrm{~b} \pm 3,52$ & $35,09 \mathrm{bcd} \pm 0,51$ \\
\hline
\end{tabular}

Valores expressos em média e desvio padrão. Nas colunas, médias seguidas de letras iguais não diferem estatisticamente (ANOVA e Teste de Tukey, $p \geq 0,05$ ).

\section{Captura do radical ABTS-+ (2,2'-azinobis (3-etilbenzotiazolina-6-ácido} sulfônico)). Para o ensaio de ABTS (Tabela 5), a maior capacidade antioxidante total foi apresentada por Synechocystis sp. (D331WC) e Scenedesmus obtusus (D209WC), que apresentaram o valor de 19,41 $\mu \mathrm{mol} \mathrm{Tx} \mathrm{g-1}$. Li et al. (2007) relatou valor correspondente analisando a microalga Chlorella pyrenoidosa $\left(15,71 \mu \mathrm{mol} \mathrm{Tx} \mathrm{g}^{-1}\right) .0$ menor resultado foi apresentado pela microalga Pediastrum boryanum (D231WC) $\left(0,16 \mu \mathrm{mol} \mathrm{Tx} \mathrm{g}^{-1}\right)$, sendo considerado um valor muito abaixo do encontrado por Goris et al. (2012), que alcançou

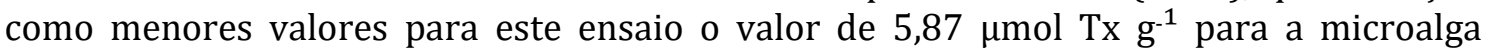
Scenedesmus obliquus. Este ensaio TEAC (Capacidade antioxidante para equivalente) 
quantifica a capacidade antioxidante por transferência de um único elétron (redução direta de ABTS) e detecta, dessa forma, a atividade antioxidante de carotenoides e polifenóis (Chatterjee, 2014).

Sequestro do radical DPPH (2,2-difenil -1-picril-hidrazil). 0 extrato metanólicos de acordo com as porcentagens de eliminação de radicais DPPH dos extratos das dez espécies de microalgas estudadas (Tabela 5) mostrou eficiente atividade de eliminação de DPPH em vários graus.

A espécie Scenedesmus quadricauda (D125WC) $\left(116,70 \mu \mathrm{mol} \mathrm{Tx} \mathrm{g}^{-1}\right)$ apresentou a maior atividade de eliminação de radicais DPPH para o extrato metanólico. Para as espécies Pediastrum duplex (D511WC) e Scenedesmus obtusus (D209WC) também se obteve valores bastante significantes $\left(67,04 \mu \mathrm{mol} \mathrm{Tx} \mathrm{g}^{-1}\right.$ e $65,38 \mu \mathrm{mol} \mathrm{Tx}^{-1}$, respectivamente). Custódio et al. (2012), obteve 35.2\% de eliminação de radicais com a utilização de extratos metanólicos $(10 \mathrm{mg} / \mathrm{ml})$ para microalga minutissima. Machado et al., (2016), encontraram valores inferiores a esse estudo (12-18\%) com a utilização de extratos metanólicos de Spirulina LEB-18 e Chlorella pyrenoidosa.

\section{Conclusões}

Os teores dos compostos químicos analisados nas biomassas das microalgas estudadas mostraram variações interespecíficas e são dependentes das condições de cultivo adotadas. Algumas espécies apresentaram consideráveis valores de proteínas (mais de 40\% do peso seco), a exemplo de Scenedesmus obtusus (D209WC) e Synechocystis sp. 1 (D331WC), podendo tais espécies serem direcionadas à aplicações em alimentos. Outras espécies, como Selenastrum gracilis (D458WC) e Xanthonema sp. (D464WC), apresentaram valores de carboidrato superiores a 40\%, sendo importantes para produção de bioetanol. Valores de lipídios superiores aos comumente encontrados na soja foram evidenciados na clorofícea Selenastrum gracilis (D458WC) e na cianobactéria Synechocystis sp.1 (D331WC) tornando-as importantes para a produção de óleos. A presença de ácidos graxos saturados em todas as espécies analisadas é relevante do ponto de vista da produção de biodiesel. As dez cepas possuem uma boa atividade antioxidante frente aos métodos utilizados, com destaque para Scenedesmus quadricauda (D125WC), que apresentou valores máximos em relação as demais espécies. Com base nas previsões das propriedades combustíveis analisadas, todas as espécies estudadas mostraram-se adequadas à produção de biodiesel, em especial as espécies Scenedesmus quadricauda (D125WC), Selenastrum gracilis (D458WC) e Coelastrum sp. (D193WC) por apresentarem todos os parâmetros requeridos para produção de biocombustível.

\section{Agradecimentos}

O presente trabalho foi realizado com apoio da Coordenação de Aperfeiçoamento de Pessoal de Nível Superior - Brasil (CAPES) - Código de Financiamento 001.

\section{Conflito de interesses}

Os autores declaram não haver conflito de interesses.

\section{Referências}

Alptekin, E.; Canakci, M. Determination of the density and the viscosities of biodiesel-diesel fuel blends. Renewable Energy, v. 33, n. 12, p. 2623-2630, 2008. https://doi.org/ 10.1016/j.renene.2008.02.020 
Araújo, G. S.; Matos, L. J. B. L.; Fernandes, J. O.; Cartaxo, S. J. M.; Gonçalves, L. R. B.; Fernandes, F. A. N.; Farias, W. R. L. Extraction of lipids from microalgae by ultrasound application: Prospection of the optimal extraction method. Ultrasonics Sonochemistry, v. 20, p. 95-98, 2013. https://doi.org/10.1016/j.ultsonch.2012.07.027

Araújo, G. S.; Matos, L. J. B. L.; Gonçalves, L. R. B.; Fernandes, F. A. N.; Farias, W. R. L. Bioprospecting for oil producing microalgal strains: Evaluation of oil and biomass production for tem microalgal strains. Bioresource Technology, v. 102, n. 8, p. 52485250, 2011. https://doi.org/10.1016/j.biortech.2011.01.089

Becker, E. W. Micro-algae as a source of protein. Biotechnology Advances, v. 25, n. 2, p. 207-210, 2007. https://doi.org/10.1016/j.biotechadv.2006.11.002

Bellinger, E. G.; Sigee, D. C. Freshwater algae: Identification and use as bioindicators. Journal of Applied Phycology, v. 25, p. 1265-1266, 2013. https://doi.org/10.1007/ s10811-012-9926-x

Bligh, E. G.; Dyer, W. J. A rapid method of total lipid extraction and purification. Canadian Journal Biochemistry Physiological, v. 27, n. 8, p. 911-917, 1959. https://doi.org/ 10.1139/059-099

Borges-Campos, V.; Barbarino, E.; Lourenço, S. O. Surgery and scientific microbial of microalgas marinhas in cultivos estanques. Ciência Rural, v. 40, n. 2, p. 339-347, 2010. https://doi.org/10.1590/S0103-84782010005000009

Branco, K. B. Z. F.; Trevisan, E.; Reis, N. V.; Arroyo, P. A. Purificação e caracterização do óleo da microalga Scenedesmus accuminatus visando à produção de biodiesel. Anais do XX Congresso Brasileiro de Engenharia Química, 2014. https://doi.org/10.5151/chemengcobeq2014-0619-24701-164909

Brand-Willams, W.; Cuvelier, M. E.; Berset, C. Use of a free radical method to evaluate antioxidant activity. LWT - Food Science and Technology, v. 28, n. 1, p. 25-30, 1995. https://doi.org/10.1016/S0023-6438(95)80008-5

Brasil. Lei no 13.033, de 24 de setembro de 2014. Dispõe sobre a adição obrigatória de biodiesel ao óleo diesel comercializado com o consumidor final; altera as Leis $\mathrm{n}^{\mathrm{O} s}$ 9.478, de 6 de agosto de 1997, e 8.723, de 28 de outubro de 1993; revoga dispositivos da Lei no 11.097, de 13 de janeiro de 2005; e dá outras providências. Disponível em: <http://www.planalto.gov.br/ccivil_03/_Ato2011-2014/2014/Lei/L13033.htm>. Acesso em: 14 ago. 2019.

Brasil. Lei no 13.263, de 23 de março de 2016. Altera a Lei no 13.033, de 24 de setembro de 2014, para dispor sobre os percentuais de adição de biodiesel ao óleo diesel comercializado no território nacional. Disponível em: <http://www.planalto.gov.br/ ccivil_03/_ato2015-2018/2016/lei/L13263.htm>. Acesso em: 14 ago. 2019.

Calixto, C. D. Potencial de microalgas regionais cultivadas em meios alternativos para produção de biodiesel. João Pessoa: Universidade Federal da Paraíba, 2016. (Tese de doutorado).

Cardoso, A. S. Avaliação do potencial das microalgas residuais como uma alternativa à cadeia produtiva do biodiesel. Anais do VII Congresso de Pesquisa e Inovação da Rede Norte e Nordeste de Educação Tecnológica, 2012.

Carneiro, G. A.; Silva, J. J. R.; Oliveira, G. A.; Pio, F. P. B. 0 uso de microalgas na produção de biocombustíveis. Research, Society and Development, v. 7, n. 5, p. 1-12, e1075181, 2018. 
Chatterjee, D.; Bhattacharjee, P. Comparative evaluation of the antioxidant efficacy of encapsulated and unencapsulated eugenol-rich clove extracts in soybean oil: Shelf-life and frying stability of soybean oil. Journal of Food Engineering, v. 117, p. 545-550, 2013. https://doi.org/10.1016/j.jfoodeng.2012.11.016

Chen, W.; Sommerfeld, M.; Hua, Q. Microwave-assisted Nile red method for in vivo quantification of neutral lipids in microalgae. Bioresource Technology, v. 102, p. 135141, 2011. https://doi.org/10.1016/j.biortech.2010.06.076

Chisti, Y. Biodiesel from microalgae beats bioethanol. Trends in Biotechnology, v. 26, n. 3, p. 126-131, 2008. https://doi.org/10.1016/j.tibtech.2007.12.002

Chisti, Y. Biodiesel from microalgae. Biotechnology Advances, v. 25, n. 3, p. 294-306, 2007. https://doi.org/10.1016/j.biotechadv.2007.02.001

Choochote, W.; Suklampoo L.; Ochaikul, D. Evaluation of antioxidant capcities of green microalgae. Journal of Applied Phycology, v. 26, n. 1, p. 43-48, 2014. https://doi.org/ 10.1007/s10811-013-0084-6

Costa Neto, P. R.; Rossi, L. F. S.; Zagonel, G. F.; Ramos, L. P. Produção de biocombustível alternativo ao óleo diesel através da transesterificação de óleo de soja usado em frituras. Química Nova, v. 23, n. 4, p. 531-537, 2000.

Costa, L. F. M. Conversão do óleo de dendê utilizando material mesoporoso para obtenção de bioquerosene. Natal: Universidade Federal do Rio Grande do Norte, 2016. (Monografia de graduação).

Custódio, L.; Justo, T.; Silvestre, L.; Barradas, A.; Duarte, C. V.; Pereira, H.; Barreira, L.; Rauter, A. P.; Alberício, F.; Varela, J. Microalgae of different phyla display antioxidant, metal chelating and acetylcholinesterase inhibitory activities. Food Chemistry, v. 131, n. 1, p. 134-140, 2012. https://doi.org/10.1016/j.foodchem.2011.08.047

Derner, R. B.; Ohse, S.; Villela, M.; Carvalho, S. M.; Fett, R. Microalgas, produtos e aplicações. Ciência Rural, v. 36, n. 6, p. 1959-1967, 2006. https://doi.org/10.1590/S010384782006000600050

Ferrari, R. A.; Souza, W. L. Avaliação da estabilidade oxidativa de biodiesel de óleo de girassol com antioxidantes. Química Nova, v. 32, n. 1, p. 106-111, 2009. https://doi.org/ 10.1590/S0100-40422009000100020

Folch, J.; Lees, M.; Stanley, G. H. S. A simple method for the isolation and purification of total lipids from animal tissues. Journal of Biological Chemistry, v. 226, p. 497-509, 1957.

Franceschini, I. M.; Burliga, A. L.; Reviers, B.; Prado, J. F.; Rézig, S. H. Algas: uma abordagem filogenética, taxonômica e ecológica. Porto Alegre: Artmed, 2009.

Francisco, E. C.; Neves, D. B.; Jacob-Lopes, E.; Franco, T. T. Microalgae as feedstock for biodiesel production: Carbon dioxide sequestration, lipid production and biofuel quality. Journal of Chemical Technology and Biotechnology, v. 85, p. 395-403, 2010. https://doi.org/10.1002/jctb.2338

Georgianna R.; Mayfield, S. P. Exploiting diversity and synthetic biology for the production of algal biofuels. Nature, v. 488, p. 329-335, 2012. https://doi.org/10.1038/nature11479 
Ghosh, A.; Khanra, S.; Mondal, M.; Halder, G.; Tiwari, O. N.; Saini , S.; Bhowmicke , T. K.; Gayen, K. Progress toward isolation of strains and genetically engineered strains of microalgae for production of biofuel and other value added chemicals. Energy Conversion and Management, v. 113, p. 104-118, 2016. https://doi.org/10.1016/ j.enconman.2016.01.050

Giovanardi, M.; Ferroni, L.; Baldisserotto, C.; Tedeschi, P.; Maietti, A.; Pantaleoni, L.; Pancaldi, S. Morphophysiological analyses of Neochloris oleoabundans (Chlorophyta) grown mixotrophically in a carbon-rich waste product. Protoplasma, v. 250, p. 161-174, 2013. https://doi.org/10.1007/s00709-012-0390-x

Gong, Y.; Jiang, M. Biodiesel production with microalgae as feedstock: From strains to biodiesel. Biotechnology Letters, v. 33, p. 1269-1284, 2011. https://doi.org/ 10.1007/s10529-011-0574-z

Guillard, R. R. L.; Lorenzen, C. J. Yellow-green algae with chlorophyllide c. Journal of Phycology, v. 8, p. 10-14, 1972. https://doi.org/10.1111/j.1529-8817.1972.tb03995.x

Halim, R. Extraction of oil from microalgae for biodiesel production: A review. Biotechnology Advances, v. 30, n. 3, p. 709-732, 2012. https://doi.org/10.1016/ j.biotechadv.2012.01.001

Harun, R.; Singh, M.; Forde, G. M.; Danquah, M. K. Bioprocess engineering of microalgae to produce a variety of consumer products. Renewable and Sustainable Energy Reviews, v. 14, n. 3, p. 1037-1047, 2010. https://doi.org/10.1016/j.rser.2009.11.004

Hindak, F. Studies on the chloroccal algae (Chlorophyceae). Bratislava: Veda Publishing House of The Slovak Academy of Sciences, 1990.

Ho, S.-H.; Lai, Y.-Y.; Chiang, C.-Y.; Chen, C.-N. N.; Chang, J.-S. Selection of elite microalgae for biodiesel production in tropical conditions using a standardized platform. Bioresource Technology, v. 147, p. 135-142, 2013. https://doi.org/10.1016/j.biortech.2013.08.028

Ho, S.-H.; Nakanishi, A.; Ye, X.; Chang, J.-S.; Hara, K.; Hasunuma, T.; Kondo, A. Optimizing biodiesel production in marine Chlamydomonas sp. JSC4 through metabolic profiling and an innovative salinity-gradient strategy. Biotechnology for Biofuels, v. 7, p. 97-113, 2014. https://doi.org/10.1186/1754-6834-7-97

Jones, J.; Manning, S.; Montoya, M.; Keller, K.; Poenie, M. Extraction of algal lipids and their analysis by HPLC and mass spectrometry. Journal of the American Chemical Society, v. 89, p. 1371-1381, 2012. https://doi.org/10.1007/s11746-012-2044-8

Khoeyi, Z. A.; Seyfabadi, J.; Ramezanpour, Z. Effect of light intensity and photoperiod on biomass and fatty acid composition of the microalgae Chlorella vulgaris. Aquaculture, v. 20, p. 41-49, 2012. https://doi.org/10.1007/s10499-011-9440-1

Knothe, G. Green chemistry. Nova York: Apple Academic Press, 2011.

Kochert, G. Carbohydrate determination by the phenol-sulfuric method. In: Hellembust, J. A., Craigie, J. S. (Eds.). Handbook of phycological methods. Cambridge: Cambridge University, 1978. p. 95-97.

Komarék, J.; Anagnostidis, K. Cyanoprokaryota. Teil: Oscillatoriales. In: Büdel, B.; Krienitz, L.; Gärtner, G.; Schagerl, M. (Eds.). Süßwasserflora von Mitteleuropa München. Amsterdam: Elsevier Spektrum Akademischer Verlag, 2005.

Lee, R. E. Phicology. 4. ed. Cambridge: Cambridge University Prees, 1999. 
Lehr, F.; Posten, C. Closed photo-bioreactors as tools for biofuel production. Current Opinion in Biotechnology, v. 20, n. 3, p.280-285, 2009. https://doi.org/ 10.1016/j.copbio.2009.04.004

Liang, Y. Producing liquid transportation fuels from heterotrophic microalgae. Applied Energy, v. 104, p. 860-868, 2013. https://doi.org/10.1016/j.apenergy.2012.10.067

Lim, D. K. Y.; Garg, S.; Timmins, M.; Zhang, E. S. B.; Thomas-Hall, S. R.; Schuhmann, H.; Li, Y.; Schenk, P. M. Isolation and evaluation of oil producing microalgae from subtropical coastal and brackish waters. PLoS One, v.7, n. 7, e40751, 2012. https://doi.org/10.1371/ journal.pone.0040751

Liu, J.; Sun, Z.; Chen, F. Biofuels from algae. Amsterdam: Elsevier, 2014. v. 6.

Lobo, I. P.; Ferreira, S. L. C.; Cruz, R. S. Biodiesel: Quality parameters and analytical methods. Química Nova, v. 32, n. 6, p. 1596-1608, 2009. https://doi.org/10.1590/S010040422009000600044

Lourenço, S. O. Cultivo de microalgas marinhas: princípios e aplicações. 1. ed. São Paulo: Rima, 2006.

Lowry, O. H.; Rosebrough, N. J.; Farr, A. L.; Randall, R. J. Protein measurement with the folin phenol reagent. The Journal of Biological Chemistry, v. 193, n. 1, p. 265-275, 1951.

Machado, A. R.; Graça, C. S.; Assis, L. M.; Souza-Soares, L. A. Uma abordagem sobre caracterização e avaliação do potencial antioxidante de extratos fenólicos de microalgas Spirulina sp. LEB-18 e Chlorella pyrenoidosa. Revista de Ciências Agrárias, v. 40, n. 1, p. 264-278, 2017. https://doi.org/10.19084/RCA16011

Mandotra, S. K.; Kumar, P.; Suseela, M. R.; Nayaka, S.; Ramteke, P. W. Evaluation of fatty acid profile and biodiesel properties of microalga Scenedesmus abundans under the influence of phosphorus, pH and light intensities. Bioresource Technology, v. 201, p. 222229, 2016. https://doi.org/10.1016/j.biortech.2015.11.042

Mata, T. M.; Martins A. A.; Caetano, N. S. Microalgae for biodiesel production and other applications: A review. Renewable \& Sustainable Energy Reviews, v. 14, n. 1, p. 217232, 2010. https://doi.org/10.1016/j.rser.2009.07.020

Medina, A. R.; Grima, E. M.; Giménez, A. G.; González, M. J. I. Downstream processing of algal polyunsaturated fatty acids. Biotechnology Advances, v. 16, n. 3, p. 517-580, 1998. https://doi.org/10.1016/S0734-9750(97)00083-9

Menezes, R. S.; Leles, M. I. G.; Soares, A. T.; Franco, P. I. B. M.; Antoniosi Filho, N. R.; Sant'Anna, C. L.; Vieira, A. A. H. Avaliação da potencialidade de microalgas dulcícolas como fonte de matéria-prima graxa para a produção de biodiesel. Química Nova, v. 36, n. 1, p. 10-15, 2013. https://doi.org/10.1590/S0100-40422013000100003

Meng, X.; Yang, J.; Xu, X.; Zhang, L.; Nie, Q.; Xian, M. Biodiesel production from oleaginous microorganisms. Renewable Energy, v. 34, n. 1, p. 1-5, 2009. https://doi.org/10.1016/ j.renene.2008.04.014

Montero, M. F.; Aristizábal, M.; Reina, G. G. Isolation of high-lipid content strains of the marine microalgae Tetraselmis suecica for biodiesel production by flow cytometry and single-cell sorting. Journal of Applied Phycology, v. 23, p. 1053-1057, 2011. https://doi.org/10.1007/s10811-010-9623-6

Moorhead, K.; Capelli, B.; Gerald, R. C. Spirulina nature's superfood. 3. ed. Havaí: Cyanotech Corporation, 2011. 
Nagarajan, M.; Maruthanayagam, V.; Sundararaman, M. A review of pharmacological and toxicological potentials of marine cyanobacterial metabolites. Journal of Applied Toxicology, v. 32, p. 153-185, 2012. https://doi.org/10.1002/jat.1717

Nascimento, I. A.; Marques, S. S. I.; Cabanelas, I. T. D.; Pereira, S. A.; Druzian, J. I.; Souza, C. O.; Vich, D. V.; Carvalho, G. C.; Nascimento, M. A. Screening microalgae strains for biodiesel production: Lipid productivity and estimation of fuel quality based on fatty acids profiles as selective criteria. BioEnergy Research, v. 6, p. 1-13, 2013. https://doi.org/10.1007/ s12155-012-9222-2

Oetterer, M.; Regitano-D’Arce, M. A. B.; Spoto, M. H. Fundamentos de ciência e tecnologia de alimentos. 5. ed. São Paulo: Manole, 2006.

Rabenhorst, L.; Geitler, L. Kryptogamen-Flora von Deutschand, Osterreich und der Schweitz: Cyanophyceae. Leipzig: Akademische Verlags-Gesellschaft, 1932. v. 14.

Ramos, M. J.; Fernández, C. M.; Casas, A.; Rodríguez, L.; Pérez, A. Influence of fatty acid composition of raw materials on biodiesel properties. Bioresource Technology, v. 100, p. 261-268, 2009. https://doi.org/10.1016/j.biortech.2008.06.039

Rattanapoltee, P.; Kaewkannetra, P. Cultivation of microalgae, Chlorella vulgaris under different auto-hetero-mixotrophic growths as a raw material during biodiesel production and cost evaluation. Energy, v. 78, p. 4-8, 2014. https://doi.org/10.1016/ j.energy.2014.06.049

Rawat, I.; Kumar, R. R.; Mutanda, T.; Bux, F. Biodiesel from microalgae: A critical evaluation from laboratory to large scale production. Applied Energy, v. 103, p. 444-467, 2013. https://doi.org/10.1016/j.apenergy.2012.10.004

Richmond, A. (Ed). Handbook of microalgal culture: Biotechnology and applied phycology. Oxford: Blackwell Science, 2004.

Rufino, M. S. M.; Alves, R. E.; Brito, E. S.; Morais, S. M.; Sampaio, C. G.; Pérez-Jiménez, J.; Saura-Calixto, F. D. Metodologia científica: determinação da atividade antioxidante total em frutas pelo método de redução do ferro (FRAP). Comunicado Técnico, n. 125, p. 1-4, 2006.

Rufino, M. S. M.; Alves, R. E.; Brito, E. S.; Morais, S. M.; Sampaio, C. G.; Pérez-Jiménez, J.; Saura-Calixto, F. D. Metodologia científica: determinação da atividade antioxidante total em frutas pela captura do radical livre DPPH. Comunicado Técnico, n. 127, p. 1-4, 2007.

Safafar, H.; Møller, P.; Holdt, S. L.; Jacobsen, S. L. Microalgal bioremediation of nutrients in wastewater and production of food/feed ingredients. Anais da DTU Sustain Conference, Lyngby, Denmark, 2015.

Selvarajan, R.; Felföldi, R.; Tauber, T.; Sanniyasi, E.; Sibanda, T.; Tekere, M. Screening and evaluation of some green algal strains (Chlorophyceae) isolated from freshwater and Soda Lakes for biofuel production. Energies, v. 8, p. 7502-7521, 2015. https://doi.org/ $10.3390 /$ en8077502

Servel, M.-O.; Claire, C.; Derrien, A.; Coiffard, L.; Roeck-Holtzhauer, Y. Fatty acid composition of some marine microalgae. Phytochemistry, v. 36, n. 3, p. 691-693, 1994. https://doi.org/10.1016/S0031-9422(00)89798-8

Silva, C. S. P.; Silva-Stenico, M. E.; Fiore, M. F.; Castro, H. F.; Da Rós, P. C. M. Optimization of the cultivation conditions for Synechococcus sp. PCC7942 (cyanobacterium) to be used as feedstock for biodiesel production. Algal Research, v. 3, p. 1-7, 2014. https://doi.org/ 10.1016/j.algal.2013.11.012 
Silva, M. S.; Naves, M. M. V.; Oliveira, R. B.; Leite, O. S. M. Chemical composition and protein value of the soybean residue in relation to the soybean grain. Food Science and Technology, v. 26 , n. 3 , p. 571-576, 2006. https://doi.org/10.1590/S010120612006000300014

Slinkard, K.; Singleton V. L. Total phenol analysis: Automation and comparison with manual methods. American Journal of Enology and Viticulture, v. 28, p. 49-55, 1977.

Stein, J. R. (Ed.). Handbook of phycological methods: Culture methods and growth measurements. Cambridge: Cambridge University Press, 1973.

Wahidin, S.; Idris, A.; Shalehc, S. R. M. The influence of light intensity and photoperiod on the growth and lipid content of microalgae Nannochloropsis sp. Bioresource Technology, v. 129, p. 7-11, 2013. https://doi.org/10.1016/j.biortech.2012.11.032

Williams, P. J. L. B.; Laurens, L. M. L. Microalgae as biodiesel \& biomass feedstocks: Review \& analysis of the biochemistry, energetics \& economics. Energy \& Environmental Science, v. 3, p. 554-590, 2010. https://doi.org/10.1039/B924978H

Zambiazi, R. U. I. C.; Przybylski, R.; Zambiazi, M. W.; Mendonça, C. B. Fatty acid composition of vegetable oils and fats. Boletim CEPPA, v. 25, n. 1, p.111-120, 2007. https://doi.org/10.5380/cep.v25i1.8399 